\title{
Some peculiarities of room-temperature ferromagnetism in ensembles of mixed-phase $\mathrm{TiN}_{\mathrm{x}}-\mathrm{TiO}_{\mathrm{y}}$ nanoparticles
}

\author{
Iurii G. Morozov $^{\mathrm{a}}{ }^{*}$, Olga V. Belousova ${ }^{\mathrm{a}}$, Sanjayan Sathasivam ${ }^{\mathrm{b}}$, Ivan P. Parkin ${ }^{\mathrm{b}}$, Maxim \\ V. Kuznetsov ${ }^{\mathrm{c}}$ \\ ${ }^{a}$ Merzhanov Institute of Structural Macrokinetics and Materials Science, Russian Academy of Sciences, Chernogolovka, Moscow Region, 142432, Russia \\ ${ }^{\mathrm{b}}$ Department of Chemistry, Materials Chemistry Research Centre, University College London, London, WC1H OAJ, United Kingdom

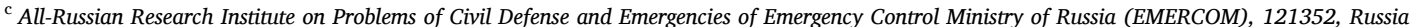

\section{A R T I C L E I N F O}

\section{Keywords:}

Nanoparticles (NPs)

Titanium nitride (TiN)

Titania $\left(\mathrm{TiO}_{2}\right)$

Room-temperature ferromagnetism (RTFM)

Spectroscopic properties of NPs

\begin{abstract}
A B S T R A C T
Mixed-phase $\mathrm{TiN}_{\mathrm{x}}-\mathrm{TiO}_{\mathrm{y}}$ nanoparticles with an average particlesize of $27-120 \mathrm{~nm}$ were prepared by the levitationjet generator through condensation of Ti metal vapor in inert gas flow with gaseous nitrogen/air additive. The nanoparticles were characterized by Scanning electron microscopy, X-ray diffraction, Ultraviolet-visible spectroscopy, Fourier transform infrared spectroscopy, Raman spectroscopy, X-ray photoelectron spectroscopy, and Vibrating sample magnetometry. Room-temperature ferromagnetism with a maximum magnetization of up to $0.14 \mathrm{emu} / \mathrm{g}$ was discovered in the nanoparticles. The observed ferromagnetic ordering was related to the defect $\mathrm{Ti}-\mathrm{N}$-O structures at the interfaces between crystal phases. This suggestion is in good correlation with data obtained during spectroscopic studies. All the results demonstrate that the predominant role of the nitrogen and oxygen vacancies at the interfaces between titanium nitride, anatase, rutile, as well as the other mixed Ti- $N$-O phases contribute to the evolution of the room-temperature ferromagnetism. The maximum saturation magnetization of nanoparticles was extremely dependent on the N/O ratio, and area of peaks core-levels N $1 \mathrm{~s}$ and $\mathrm{O} 1 \mathrm{~s}$. For the first time, an unknown phenomenonof a temporary "turn-off" effect of magnetization in hysteresis loops of some mixed-phase nanoparticles was discovered. The obtained results could be used in the search for new spintronic materials.
\end{abstract}

\section{Introduction}

Dilute magnetic semiconductors are the most representative class of ferromagnetic materials operating at room temperature (RTFM). RTFM detection reports continue to appear even for vanishing concentrations of magnetic atoms and are still one of the most controversial topics in magnetism [1]. Various improper sources of such ferromagnetic behavior (instrumental artifacts, alien magnetic impurities, etc.) have become well documented, but they are rarely taken into account when ferromagnetism of initially non-magnetic bulk materials at room temperature are reported [1-3]. From the single element material (graphite) to several covalently bonded non-magnetic compounds (for example, oxides, nitrides, selenides, etc.), the influence of defects such as vacancies and/or non-magnetic atoms on triggering magnetic order is attracting the interest of theoreticians [4]. But, in general, their model description is still not quite adequate, since various chemical compounds show different behavior concerning the origin of RTFM, apparently due to the features of their defect structure, especially in the nanostructured states of material [1].

Among the studied materials, systems based on practically important Ti-compounds in the form of nanoparticles (NPs) or thin films of Ti-N [5, 6], Ti-O [7,8], and $\mathrm{N}-\mathrm{TiO}_{2}$ [9] are very interesting, when RTFM occurs without the participation of any other alloying components and its mechanism is encouraged for discussion.

In many studies, related to NPs of undoped $\mathrm{TiO}_{2}$, RTFM was strongly dependent on nanoparticle production procedure and techniques of treatment. Firstly, Zhao et al., using sol-gel method, prepared of $\mathrm{TiO}_{2}$ NPs in anatase $(\sim 10 \mathrm{~nm})$ and rutile $(\sim 20 \mathrm{~nm})$ forms, which after annealing under $\mathrm{H}_{2} / \mathrm{Ar}$ atmosphere achieved specific saturation magnetization $\left(\sigma_{\mathrm{s}}\right)$ of up to 9 and $5 \mathrm{memu} / \mathrm{g}$, respectively [10].Further, other researchers have used the sol-gel approach with different post-treatment. Wen et al. discovered only superparamagnetic-like behavior in $\mathrm{TiO}_{2} \mathrm{NPs}$ of a few $\mathrm{nm}$ in sizes [11].Choudhury et al. obtained $\sigma_{\mathrm{s}} \sim 183 \mathrm{memu} / \mathrm{g}$ in the NPs of anatase-brookite $(7-10 \mathrm{~nm})$ [12]. 
Table 1

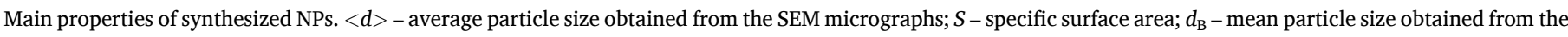
BET analysis; $\sigma_{\mathrm{s}}$ - saturation magnetization.

\begin{tabular}{|c|c|c|c|c|c|c|c|c|c|}
\hline \multirow{2}{*}{ ID } & \multicolumn{5}{|c|}{ Synthesis conditions } & \multirow[b]{2}{*}{$S, \mathrm{~m}^{2} / \mathrm{g}$} & \multirow[b]{2}{*}{$<d>, \mathrm{nm}$} & \multirow[b]{2}{*}{$d_{\mathrm{B}}, \mathrm{nm}$} & \multirow[b]{2}{*}{$\sigma_{\mathrm{s}}, \mathrm{memu} / \mathrm{g}$} \\
\hline & $\mathrm{Ti}, \mathrm{g} / \mathrm{h}$ & Ar, $1 / \mathrm{h}$ & $\mathrm{He}, 1 / \mathrm{h}$ & air, 1/h;mode & $\overline{\mathrm{N}_{2}, \mathrm{l} / \mathrm{h} \text {;mode }}$ & & & & \\
\hline TNO1 & 2 & 130 & 0 & 280; SA & 0 & $18.4 \pm 0.18$ & 120 & 70 & 14 \\
\hline TNO2 & 0.5 & 80 & 0 & $\begin{array}{l}1 ; \\
\text { CA }\end{array}$ & $\begin{array}{l}21 \\
\mathrm{CA}\end{array}$ & $34.25 \pm 1.07$ & 66 & 40 & 29 \\
\hline TNO3 & 5 & 130 & 0 & $\begin{array}{l}1 ; \\
\text { CA }\end{array}$ & $\begin{array}{l}120 \\
\text { SA }\end{array}$ & $19.74 \pm 0.12$ & 100 & 57 & 30 \\
\hline TNO4 & 5 & 130 & 0 & $\begin{array}{l}1 ; \\
\text { CA }\end{array}$ & $\begin{array}{l}34 \\
\text { SA }\end{array}$ & $27.96 \pm 1.18$ & 95 & 40 & 54 \\
\hline TNO5 & 5 & 130 & 0 & $\begin{array}{l}1 ; \\
\text { CA }\end{array}$ & $\begin{array}{l}120 \\
\text { SA }\end{array}$ & $18.77 \pm 0.63$ & 105 & 62 & 45 \\
\hline TNO6 & 5 & 0 & 430 & $\begin{array}{l}1 ; \\
\text { CA }\end{array}$ & $\begin{array}{l}37 \\
\mathrm{SH}\end{array}$ & $68.01 \pm 0.49$ & 27 & 17 & 80 \\
\hline TNO7 & 2 & 130 & 0 & $\begin{array}{l}1 ; \\
\text { CA }\end{array}$ & $\begin{array}{l}0 \\
\mathrm{CA}\end{array}$ & $12.22 \pm 0.46$ & 110 & 100 & 91 \\
\hline TNO8 & - & - & - & - & - & $24.45 \pm 1.03$ & 95 & 60 & 140 \\
\hline TNO9 & 5 & 0 & 430 & $\begin{array}{l}1 ; \\
\mathrm{CH}\end{array}$ & 0 & $36.25 \pm 0.77$ & 60 & 34 & $\begin{array}{l}17 / \sim 0 \\
\text { Switch behavior }\end{array}$ \\
\hline
\end{tabular}

Ghosh et al. synthesized NPs (5-20 nm) with $\sigma_{\mathrm{s}}$ of up to $0.32 \mathrm{emu} / \mathrm{g}$ [13].Gómez-Polo et al. obtained anatase titania NPs $(\sim 5-8 \mathrm{~nm})$ with only paramagnetic behavior and up to $3.5 \mathrm{memu} / \mathrm{g}$ for $\mathrm{N}$-doped samples [14].Patel et al. manufactured anatase NPs $(15-40 \mathrm{~nm})$ with $\sigma_{\mathrm{s}} \sim 5$ $\mathrm{memu} / \mathrm{g}[15]$.Q. Wang et al. synthesized anatase NPs $(\sim 18 \mathrm{~nm})$ with $\sigma_{\mathrm{s}}$ of up to $1.7 \mathrm{memu} / \mathrm{g}$ [16].Singh et al. observed $\sigma_{\mathrm{s}}$ of up to $2 \mathrm{memu} / \mathrm{g}$ in anatase/rutile NPs (10-60 nm) [17].Rajkumar and Ramachandran obtained anatase NPs $(5-10 \mathrm{~nm})$ with $\sigma_{\mathrm{s}} \sim 45 \mathrm{memu} / \mathrm{g}$ using a chemical route [18].Chanda et al. found $\sigma_{\mathrm{s}}$ of up to $8 \mathrm{memu} / \mathrm{g}$ in the wet-chemical $\mathrm{TiO}_{2} \mathrm{NPs}(6-10 \mathrm{~nm})$ [19].Parras et al. prepared NPs of rutile $\mathrm{TiO}_{2-\delta}(10$ $\mathrm{nm})$ with $\sigma_{\mathrm{s}} \sim 10 \mathrm{memu} / \mathrm{g}$ [20] by hydrolyze. S. Wang et al. prepared anatase NPs $(20-30 \mathrm{~nm})$ with $\sigma_{\mathrm{s}}$ of up to $25 \mathrm{memu} / \mathrm{g}$ using a solvothermal treatment method [21].

Experimental investigations of hysteresis magnetization in aerosolgenerated NPs shown that maximum specific magnetization can reach $2.5 \mathrm{emu} / \mathrm{g}$ in the titanium nitride [22], and $0.2 \mathrm{emu} / \mathrm{g}$ in titania [23]. In these NPs, manufactured using a levitation-jet generator, it was found that for the Ti-N system saturation magnetization fluctuates with the values of indirect bandgap and tends to increase with higher Ti-N bond concentrations. This behavior was interpreted in terms of the defect structure of the NPs surface containing vacancies of Ti $\left(\mathrm{V}_{\mathrm{Ti}}\right)$ and $\mathrm{N}\left(\mathrm{V}_{\mathrm{N}}\right)$ [22]. For the Ti-O NPs saturation magnetization monotonically changed depending on their specific surface area, average particle size, and rutile content [23]. Such behavior was also interpreted in terms of the defective structure of anatase/rutile interface, containing $\mathrm{V}_{\mathrm{Ti}}$ and oxygen $\left(\mathrm{V}_{\mathrm{O}}\right)$ vacancies. The concentration and degree of interaction of defects in all the above-mentioned systems could be controlled by variations in the preparation conditions, such as particle size, morphology, and chemical composition of NPs.

Theoretical studies indicated, that cationic vacancies could be ferromagnetically coupled [24]. Furthermore, several experimental data have shown that the magnetic properties of undoped titanium dioxide are closely related to oxygen vacancies, which are thus considered to be a source of RFTM [25]. The electronic state induced by oxygen vacancies was also studied using first-theoretical calculations in rutile and anatase [26]. However, it is interesting to find out which T-N or Ti-O subsystem has a stronger effect on RTFM since all samples are usually exposed to open air before the test procedures. We believe that the real structure of defects is such that an uneven distribution of defects over the material [27] can lead to the formation of some local stable states (pseudo phases), where defects are interacting (including with the matrix) with RTFM generation [28]. In this case, the amplitude of the RTFM response should be directly proportional to the content of such phases. The question is, what the key factor is in the development of RTFM:the presence of defects, such as $\mathrm{V}_{\mathrm{O}}, \mathrm{V}_{\mathrm{N}}, \mathrm{V}_{\mathrm{Ti}}$, or their uneven distribution over the material. Since metallic titanium is the same component in such mixed systems, the difference in the ability of gas ions to penetrate the crystal lattice and/or in the level of adsorption (accommodation) of surface atoms can be determined using optical and spectral data, as well as XPS data.

In this paper, we synthesized some mixed phases from $\mathrm{TiN}_{\mathrm{x}}-\mathrm{TiO}_{\mathrm{y}}$ nanoparticles using the levitation-jet generator and tried to find out any features in their magnetic, structural, and optical/spectral characteristics, that distinguish this material from the previously studied Ti-N or TiO systems [22,23].

\section{Experimental}

\subsection{Synthesis}

Composite $\mathrm{TiN}_{\mathrm{x}}-\mathrm{TiO}_{\mathrm{y}}$ nanoparticles were synthesized using the levitation-jet generator described in detail elsewhere [22,23]. A twisted piece of titanium wire (Sigma-Aldrich, diam. $0.25 \mathrm{~mm}, 99.7 \%$ purity) was suspended on the bottom edge of wire inside of a quartz tube. This piece was heated up by the electromagnetic field $(0.44 \mathrm{MHz})$ generated using counter-current inductor until metal Ti began to levitate, melt, vaporize and then condensate in the form of aerosol nanoparticles [29]. A vaporizing liquid droplet was blown down by an adjustable stream of $\operatorname{Ar}$ (99.998 at. \%) or He (99.995 at. \%) gas and permanently supplied by the Ti metal wire. To obtain NPs with desirable composition gaseous nitrogen (99.996 at. \%) and air (99.99 at. \%) as reactive gases were permanently injected in the base stream in the given ratio. During all the synthesizes well-known actions have been taken to prevent any influence of undesirable magnetic contaminants [2].

Most of the NPs understudy were prepared when the reactive gas was added to Ar or He based flow through a lower input in the split mode (SA or SH, respectively, [29]). For three cases of NPs synthesis the reactive gas was added into Ar or He based flows through an upper input in CA or $\mathrm{CH}$ combined mode, respectively [29]. One part of the as-prepared TNO9 sample underwent combustion in the open air and was takenas a TNO8 sample. The specificity of all the above-mentioned conditions was the manufacture of NPs with varied phase compositions and average particle size [29]. All the parameters of NPs synthesis, including metal feed rate, inert and reactive gas flow rates, synthesis mode, etc. are listed in Table 1.

\subsection{NPs characterization}

The NPs morphology and particle sizes were examined using scanning electron microscopes (SEM) CARL ZEISS: LEO1450 and ULTRA 

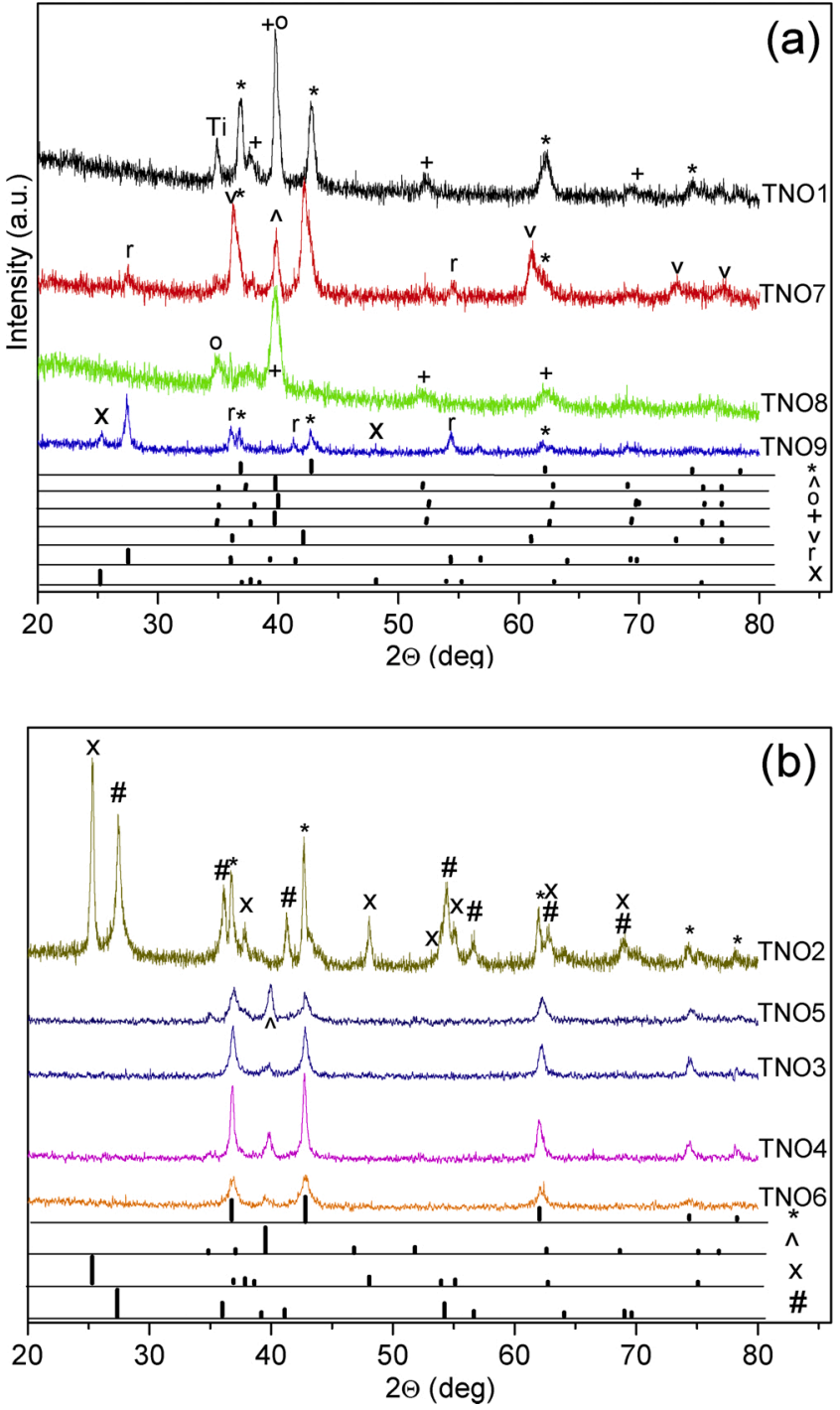

Fig. 1. XRD patterns of all the NPs. The numbers of curves correspond to the numbers of NPs in Tables 1 and 2. The main crystalline phases are Osbornite 870632 (*), 72-1807 (o), 73-1116 (^), 73-1581 (+), 65-1119 (\#), 86-2352 (v), rutile 89-4920 (r), and anatase 84-1285 (x). The XRD standard patterns are presented in the low part of both plots.

PLUS. Electron micrographs were analyzed using Carl Zeiss AxioVision image processing software. As a result of that, the particle size distribution and their volume average size $<d>$ were determined [29]. The specific surface area of NPs was studied by four-point $\mathrm{N}_{2}$ physical sorption BET measurements using the META SORBI-M instrument. The crystal structure of NPs was determined by using an X-ray powder diffractometer DRON-3 M ( $\mathrm{Cu} K \alpha$ radiation). The phase composition of NPs was determined using JCPDS PDF2 (release 2011) and Crystallographica SearchMatch software. Rietveld analysis (PowderCell 2.0 software) of X-ray diffraction patterns was applied to evaluate the fraction of crystalline phases in nanoparticles. UV-vis spectra of NPs were recorded using Lambda950 (Perkin Elmer). Fourier transform infrared (FT-IR) spectra were acquired using the Tensor 27 spectrometer (Bruker) in the frequency range of $400-4000 \mathrm{~cm}^{-1}$. Raman spectra were recorded using the InVia Raman Renishaw apparatus (Ar laser, 514.5 $\mathrm{nm})$. XPS instrument was a Thermo Scientific X-ray Photoelectron Spectrometer (Al $K \alpha, 1486.6 \mathrm{eV}$ source) running at $72 \mathrm{~W}$ with a pass energy of $50 \mathrm{eV}$. For calibration of XPS spectra, the Carbon $1 \mathrm{~s}$ spectrum was recorded for all the samples. Magnetic properties of NPs were measured by EG\&G PARC M4500 vibrating sample magnetometer in applied magnetic fields of up to $10 \mathrm{kOe}$ with a relative accuracy of $1 \times$ $10^{-4}$ at room temperature. A diamagnetic contribution of the nylon sample container was extracted from the total response to determine the true magnetic moment of samples.

\section{Results and discussion}

\section{1. $X R D$}

All the NPs were found as Ti-N/Ti-O composite materials with various crystal structures. Fig. 1 demonstrates XRD patterns for all NPs (with their JCPDS card numbers) under study. In Table 2, the results of crystal phase identification with its percentage were summarized. As it is seen, the main $\mathrm{T}-\mathrm{N}$ phases were osbornites $\operatorname{TiN}_{(\mathrm{x})}$. The main Ti-O phases were titanium oxides including rutile and anatase. Using cumulative calculations, we estimated N/O ratio for all the NPs. These values are also presented in Table 2 .

\subsection{SEM}

Fig. 2 shows SEM micrographs of some NPs. In Fig. 2a, the TNO6 NPs are tenths of $\mathrm{nm}$ in size and commonly rough cubic shapes are seen. These shapes are in good correlations with the results of ref. [22], because of the large quantity of Ti-N phases in the NPs composition (Table 2). In Fig. S1 (Supplementary data) particle size distribution of the NPs extracted from the corresponding SEM image showing the fit to a log-normal distribution function. In Fig. 2b the TNO7 NPs are seen to be from tenths to hundreds of $\mathrm{nm}$ in size, commonly rounded morphology and plate-liked (welded spheres), which are in a good correlation with the results of ref. [23]. Both NPs micrographs included the minor component as a counter partner to each other. The particle size distributions of both NPs were moderately narrow and log-normal [29]. Table 1 lists specific surface areas (S) calculated from BET measurements of various NPs, allowing us roughly estimated a degree of their surface evolution and the mean particle size - $d_{\mathrm{B}}$. Average volume sizes $<d>$ obtained from the analysis of NPs micrographs are also presented in Table 1. As it is seen from Table 1 , the $<d>$ and $d_{\mathrm{B}}$ values are in good correlation.

\subsection{Magnetic properties}

VSM measurements showed that NPs have ferromagnetic hysteresis loops at room temperature (RT). The results of specific magnetization $\sigma$ measurements for all the NPs $v s$. applied magnetic field, $H$, are presented in Fig. 3a. Hysteresis loops exhibit soft-magnetic behavior with coercivity ranged within 40-130 Oe. In Tables 1 and 2, the saturation magnetization $\sigma_{\mathrm{s}}$ data are reported. The highest saturation magnetization value obtained in this study was about $0.14 \mathrm{emu} / \mathrm{g}$ (NPs TNO8), which was smaller than $\sigma_{\mathrm{s}}$ values, obtained for the above-mentioned single-phase $\mathrm{TiN}$ or $\mathrm{TiO}_{2}$ NPs samples [22,23].

However, amazing magnetic behavior has been discovered in some of the NPs. In Fig. 3b we can observe strange reversible traces of the instability of the VSM signal from the TNO 9 NPs with rather low nitrogen content. This sample demonstrates a temporary "turn-off" effect of magnetization in hysteresis loops of some NPs when an applied magnetic field changes. Such a magnetic phenomenon can be attributed to the influence of local regions in NPs with various defective structures at the interphase boundaries [18-20]. It is interesting to note, that after the combustion of these NPs in the open air they undergo radical transformations in their composition (cf. TNO9 and TNO8 NPs data, Table 2). The saturation magnetization of burnt NPs has increased sharply and the "turn-off" effects have relatively weakened, retaining its absolute value. It can be assumed, that configuration of the defects is affected by the rate of changes in an applied magnetic field (about 28 Oe per second). The field is capable of destroying the weak RTFM interactions between defects, periodically reconfiguring the percolation 
Table 2

Crystalline phases of NPs identified from XRD patterns and their content, determined by the Rietveld analysis.

\begin{tabular}{|c|c|c|c|c|c|c|c|c|}
\hline \multirow{3}{*}{ ID } & \multicolumn{6}{|c|}{ XRD composition } & \multirow{3}{*}{$\mathrm{N} / \mathrm{O}$} & \multirow{3}{*}{$\sigma_{\mathrm{s}}, \mathrm{memu} / \mathrm{g}$} \\
\hline & \multicolumn{3}{|c|}{ Ti-N (Ti) component } & \multicolumn{3}{|c|}{ Ti-O component } & & \\
\hline & Card & Name/ Formula & at. $\%$ & Card & Name/ Formula & at. $\%$ & & \\
\hline \multirow{3}{*}{ TNO1 } & & & & $86-2352$ & Titanium Oxide/ TiO & 43 & \multirow{3}{*}{0.3} & \multirow{3}{*}{14} \\
\hline & $87-0629$ & Osbornite, syn/ TiN & 28 & $73-1116$ & Titanium Oxide $/ \mathrm{Ti}_{2} \mathrm{O}$ & 16 & & \\
\hline & & & & $89-4920$ & Rutile, syn/ $\mathrm{TiO}_{2}$ & 13 & & \\
\hline \multirow{3}{*}{ TNO2 } & $87-0626$ & Osbornite, syn/ $\mathrm{NTi}_{0.76}$ & 21 & $84-1285$ & Anatase, syn/ $\mathrm{TiO}_{2}$ & 42 & \multirow{3}{*}{4.1} & \multirow{3}{*}{29} \\
\hline & \multirow{2}{*}{$87-0632$} & \multirow{2}{*}{ Osbornite, syn/ TiN } & \multirow{2}{*}{13} & $65-1119$ & Titanium Oxide/ $\mathrm{TiO}_{2}$ & 19 & & \\
\hline & & & & $73-1776$ & Titanium Oxide/ $\left(\mathrm{TiO}_{0.995}\right)_{3.42}$ & 5 & & \\
\hline TNO3 & $87-0632$ & Osbornite, syn/ TiN & 82 & $72-1471$ & Titanium Oxide $/ \mathrm{Ti}_{6} \mathrm{O}$ & 18 & 4.6 & 30 \\
\hline \multirow{2}{*}{ TNO4 } & $87-0632$ & Osbornite, syn/ TiN & 72 & \multirow{2}{*}{$76-1644$} & \multirow{2}{*}{ Titanium Oxide/ $\mathrm{Ti}_{3} \mathrm{O}$} & \multirow{2}{*}{16} & \multirow{2}{*}{5.3} & \multirow{2}{*}{54} \\
\hline & $65-0414$ & Osbornite, syn/ TiN & 12 & & & & & \\
\hline \multirow[t]{2}{*}{ TNO5 } & $87-0632$ & Osbornite, syn/ TiN & 40 & \multirow[t]{2}{*}{$73-1116$} & \multirow{2}{*}{ Titanium Oxide $/ \mathrm{Ti}_{2} \mathrm{O}$} & \multirow[t]{2}{*}{36} & \multirow{2}{*}{3.6} & \multirow{2}{*}{45} \\
\hline & $\begin{array}{l}87-0630 \\
87-0632\end{array}$ & $\begin{array}{l}\text { Titanium Nitride/ }(\mathrm{TiN})_{0.88} \\
\text { Osbornite, syn/ TiN }\end{array}$ & $\begin{array}{l}24 \\
35\end{array}$ & & & & & \\
\hline \multirow[t]{2}{*}{ TNO6 } & $87-0630$ & Titanium Nitride/ $(\mathrm{TiN})_{0.88}$ & 33 & \multirow[t]{2}{*}{$65-6711$} & \multirow[t]{2}{*}{ Titanium Oxide $/ \mathrm{Ti}_{2.5} \mathrm{O}_{3}$} & \multirow[t]{2}{*}{13} & \multirow[t]{2}{*}{1.9} & 80 \\
\hline & $76-1834$ & $\alpha$-Titanium Nitride/ $\operatorname{TiN}_{0.61}$ & 19 & & & & & \\
\hline TNO7 & $87-0632$ & Osbornite, syn/ TiN & 18 & $73-1581$ & Titanium Oxide/ $\mathrm{TiO}_{0.325}$ & 47 & & 91 \\
\hline INU/ & $65-9622$ & $\alpha$-Titanium/ Ti & 15 & $72-1807$ & Titanium Oxide $/ \mathrm{Ti}_{6} \mathrm{O}$ & 20 & 1.0 & 91 \\
\hline & & & & $73-1782$ & Rutile, syn/ $\mathrm{TiO}_{1.95}$ & 32 & & \\
\hline TNO8 & $87-0632$ & Osbornite syn/ TiN & 18 & $65-0192$ & Rutile, syn/ $\mathrm{TiO}_{2}$ & 30 & 0.1 & 140 \\
\hline 1NU8 & $8 /-0032$ & UsDornite, syn/ hiv & 18 & $84-1285$ & Anatase, syn/ $\mathrm{TiO}_{2}$ & 12 & 0.1 & 140 \\
\hline & & & & $72-0519$ & Titanium Oxide/ $\mathrm{Ti}_{3} \mathrm{O}_{5}$ & 8 & & \\
\hline & $76-0198$ & & & $89-3074$ & Titanium Oxide/ $\mathrm{TiO}_{0.48}$ & 24 & & $17 / \sim 0$ \\
\hline TNO9 & $10-0190$ & 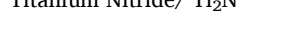 & 9 & $73-1581$ & Titanium Oxide/ $\mathrm{TiO}_{0.325}$ & 21 & 0.2 & \\
\hline INUY & $89-2959$ & Titanium/Ti & 19 & $73-1583$ & Titanium Oxide/ $\mathrm{Ti}_{3} \mathrm{O}$ & 17 & 0.2 & Switch behavior \\
\hline & $09-2909$ & itcamlum/ 11 & 19 & $72-1807$ & Titanium Oxide/ $\mathrm{Ti}_{6} \mathrm{O}$ & 10 & & \\
\hline
\end{tabular}
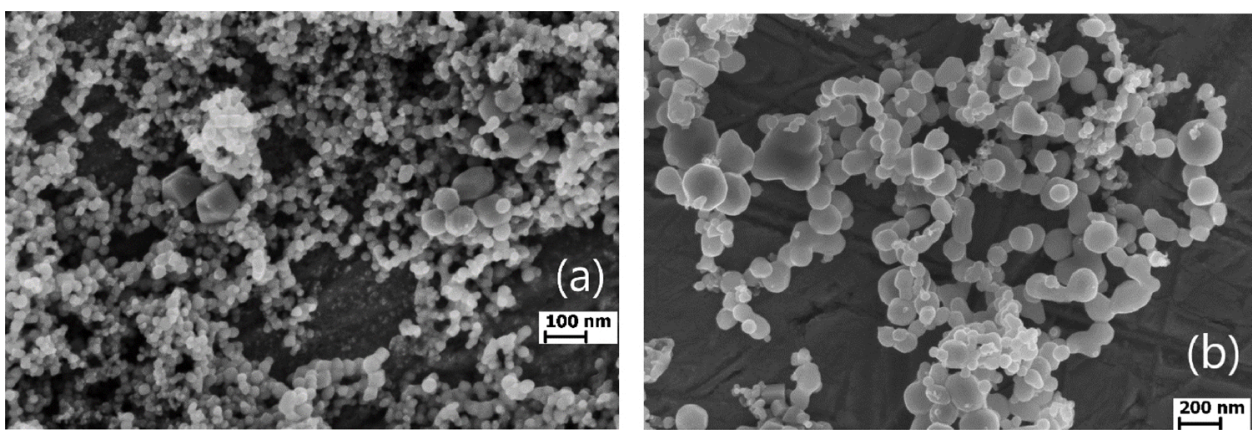

Fig. 2. Representative SEM micrographs of some NPs listed in Table 1: (a) TNO6, (b) TNO7.
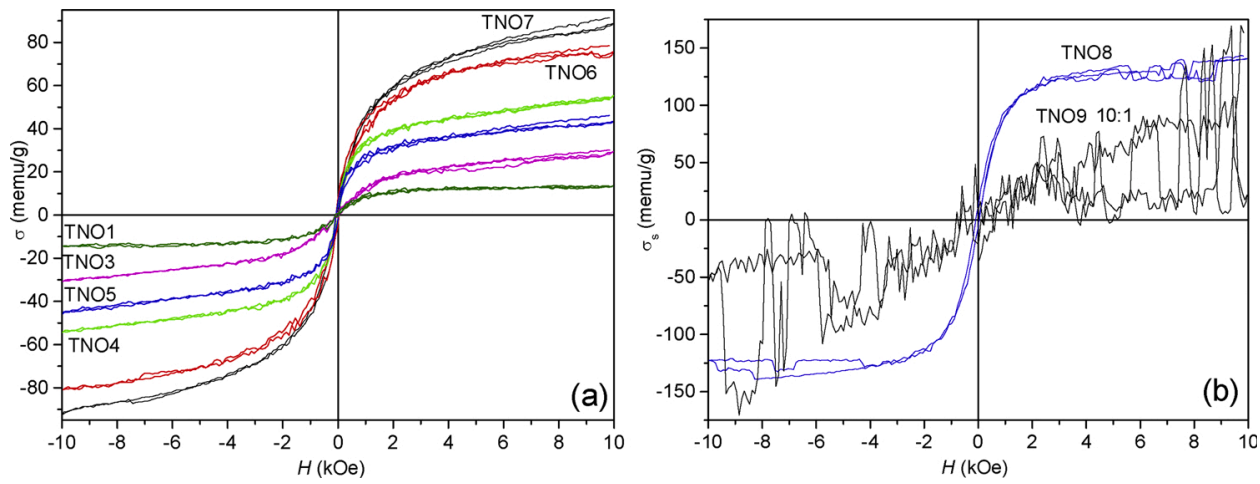

Fig. 3. Ferromagnetic hysteresis loops of some NPs from Table 1 . The numbers of curves correspond to the numbers of NPs in Table 1.

network of connecting various types of vacancies, which determines the total magnetic moment of the system.

Since there is still no complete understanding of the RTFM origin during nanostructuring of initially bulk non-magnetic materials [30], the main goal of this study was to find out how the magnetization of NPs depends on other characteristics of the material under study [31-33].
Table 1 does not show any explicit dependencies of saturation magnetization from the average particle size. At the same time, in Fig. 4, a dependence of $\sigma_{\mathrm{s}}$ from the phase composition of NPs plotted as a function of the N/O ratio, demonstrates some maxima. Such behavior can also be interpreted in terms of the defect structure of nanoparticles [34]. As was mentioned above, the randomly distributed vacancy regions of 


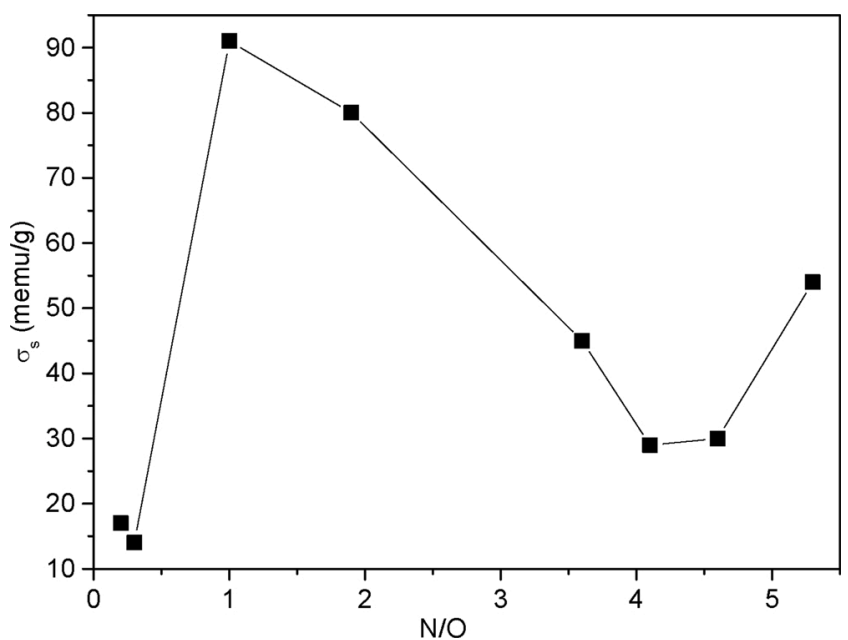

Fig. 4. Saturation magnetization vs. phase composition of as-prepared NPs.

titanium, oxygen, and nitrogen may be presented in the studied material [35]. Such defects can limit the compensating charges in molecular orbitals, forming local magnetic moments, and RTFM can be established only if these defects concentrations significantly exceeds the equilibrium value [28]. As a result of that, the $\sigma_{\mathrm{s}}$ value of samples should depend on the number of such moments, associated with the density of defects at the phase boundaries [28]. As is seen in Fig. 4, for as-prepared $\mathrm{TiN}_{\mathrm{x}}-\mathrm{TiO}_{\mathrm{y}}$ nanoparticles $\sigma_{s}$ reach its maximum when the N/O ratio is unity. Then it can be assumed, that number of vacancies of nitrogen and oxygen atoms in the system, in this case, will also be the same. Since maximum $\sigma_{\mathrm{s}}$ values, which have been achieved in the nanoparticles of the Ti-N and Ti-O systems, are higher than its value for the mixed phase, it can also be assumed, that here interfaces completely determine the evolution of RTFM. As nitrogen and oxygen vacancies in the crystal lattice at the interface can compete for the interactions with titanium vacancies, the
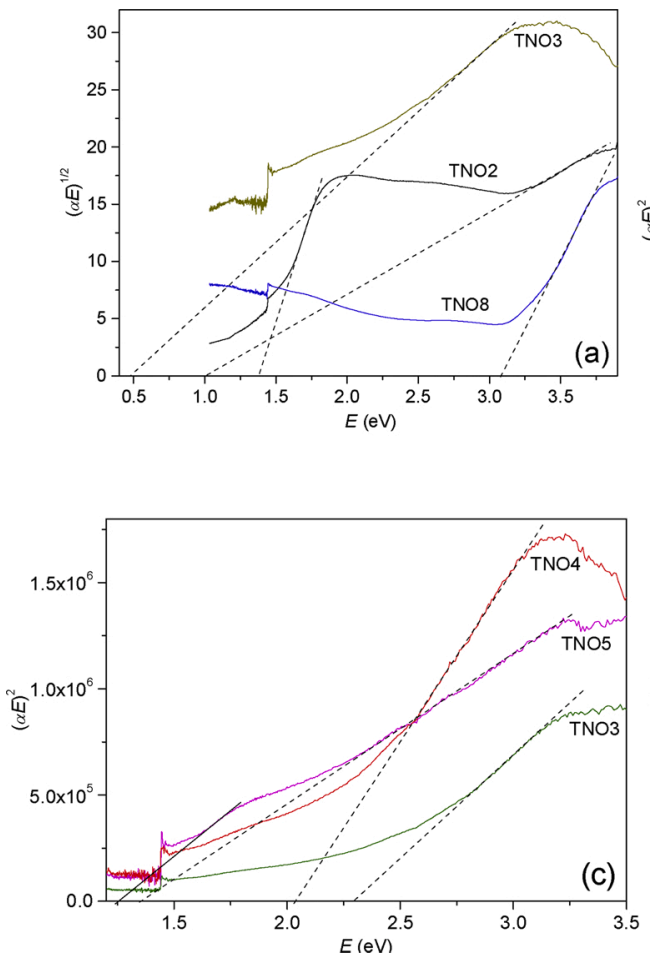

stability of the Ti- $\mathrm{N}-\mathrm{O}$ system can be violated when the magnetic field was applied. Such RTFM in a mixed-phase material will be sensitive to the rapid changes in the applied magnetic field. This indicates a rather weak interaction between single magnetic moments of vacancy configurations in RTFM of systems with insufficient vacancy density. Combustion of such sample in air expands the percolation networks, increasing the $\mathrm{V}_{\mathrm{O}}$ density over a larger volume of the sample. However, while stabilizing the value of total magnetization, there is a possibility of maintaining ability for magnetic field temporarily to disable the rest localized interface areas (probably related to $\mathrm{V}_{\mathrm{N}}$ ).

\subsection{Optical characterization of NPS}

\subsubsection{UV-vis reflectance}

Optical properties of NPs were studied using UV-vis spectroscopy by measuring spectra in the range of $200-1200 \mathrm{~nm}$ in a diffuse reflectance mode [36] (Fig. S2).

The optical band gap energy $\left(E_{\mathrm{g}}\right)$ of the NPs were estimated using Tauc equation [37]:

$\alpha E=A\left(E-E_{\mathrm{g}}\right)^{l} / q$,

where $\alpha$ is an absorption coefficient, which may be obtained from the reflectance $R$ using Kubelka-Munk function [38], $E=\mathrm{h} \nu$ is an incident photon energy, $A$ is a constant, and $q$ is an index that characterizes optical absorption process $(q=2$ for direct and 0.5 for indirect processes).

Tauc plots of $(\alpha E)^{1 / 2}$ vs. (E) (Fig. 5a) and $(\alpha E)^{2}$ vs. (E) (Figs. 5b,c) were used to evaluate the indirect $\left(E_{\text {gi }}\right)$ and direct $\left(E_{\text {gd }}\right)$ bandgap energies, respectively, by extrapolating the linear region of plots to intersect the photon energy axis.

From Fig. 5a it was found that the indirect bandgap $\left(E_{g i}\right)$ values of NPs are $0.5 ; 1.0 ; 1.39$ and $3.08 \mathrm{eV}$. The last value is close to $E_{\mathrm{g}}$ value, corresponding to the bandgap energy, determined in $\mathrm{N}^{-\mathrm{TiO}_{2}}$ thin films [39]. In this Fig., a decrease in the $E_{\text {gi }}$ bandgap values of the NPs was related to an increase in $\mathrm{N}$ content (see also Fig. 5d) may be seen.
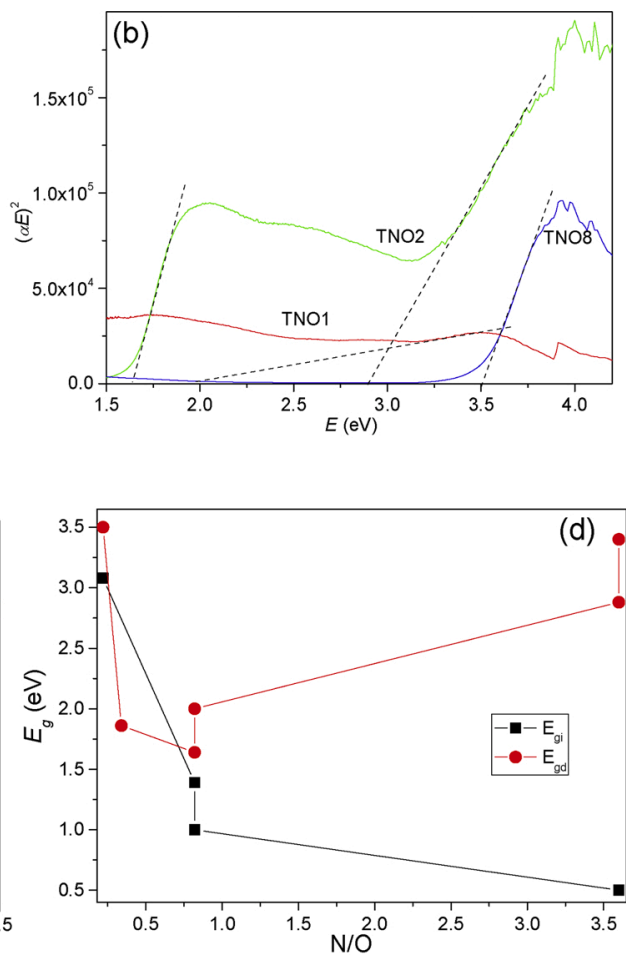

Fig. 5. Tauc plots of $(\alpha E)^{1 / q} v s . E$ for some of the NPs for the different $q$ : (a) 2; (b, c) 0.5. The numbers of curves correspond to the numbers of NPs in Table 1. (d) Energy gaps dependencies from the N/O ratio in the NPs. 


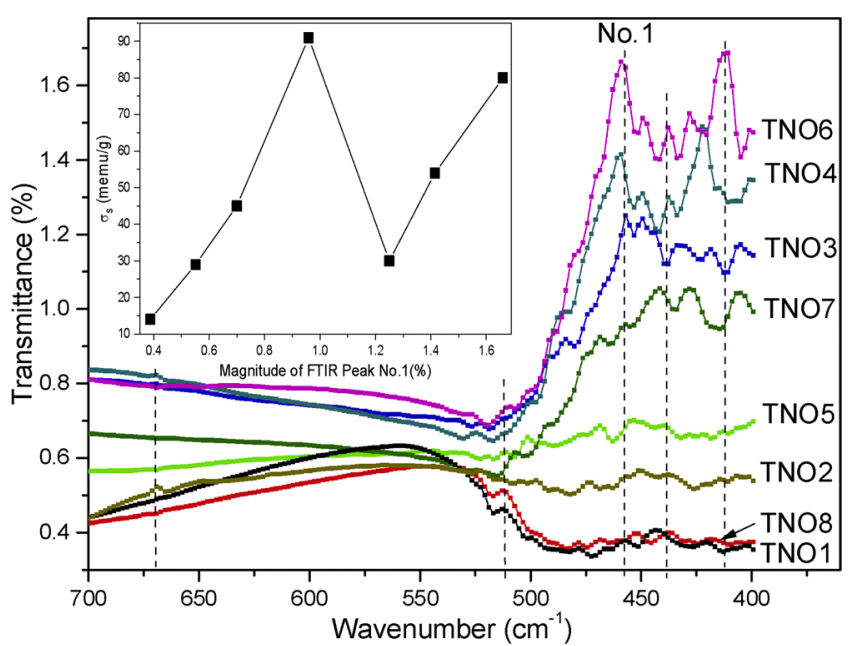

Fig. 6. IR bands of NPs in the range of $400-700 \mathrm{~cm}^{-1}$. The inset - dependence of saturation magnetization from the magnitude of FTIR peak No.1 for asprepared NPs. The numbers of curves correspond to the numbers of NPs in Tables 1 and 2 .

Figs. 5b,c demonstrates the results of direct bandgap determination, which have a much better fit than the corresponding fit of indirect bandgap, since in this case, the light absorption does not involve a change in the electron-hole pair momentum [40]. The $E_{\mathrm{g}}(\mathrm{N} / \mathrm{O})$ dependence of theNPs shows a wide dip character, as is seen in Fig. 5d. Such behavior has been, probably, related to the peculiarity of $\mathrm{O}^{2-}>\mathrm{Ti}^{4+}$ charge transfer in such systems [41]. Some of these band gap values have been earlier reported for $\mathrm{TiO}_{\mathrm{x}} \mathrm{N}_{\mathrm{y}}$ films deposited by reactive magnetron sputtering [42].

It is widely known, that the filled $\mathrm{O} 2 \mathrm{p}$ orbital and empty $\mathrm{Ti} 3 \mathrm{~d}$ orbital mainly forms the valence and conduction bands of $\mathrm{TiO}_{2}$. The low energy $\mathrm{N} 2 \mathrm{p}$ orbital atom considerably interacts with that of $\mathrm{O} 2 \mathrm{p}$, leading to a charge transfer between $\mathrm{N} 2 \mathrm{p}$ and conduction or valence band. As a result of that, there is red-shift in the bandgap transitions [43], as it was discovered in the NPs.

\subsubsection{FT-IR}

FT-IR transmittance spectra of some NPs in the frequency region of $400-4000 \mathrm{~cm}^{-1}$ were also recorded (Fig. S3). The band around 2350 $\mathrm{cm}^{-1}$ was assigned to the surface-adsorbed $\mathrm{CO}_{2}$ from ambient air [44]. The weak peak at $1150 \mathrm{~cm}^{-1}$ can be attributed to the $\mathrm{O}-\mathrm{H}$ vibrations of the hydroxyl species (Ti-O-O- $\mathrm{H} \mathrm{[45])} \mathrm{also} \mathrm{formed} \mathrm{at} \mathrm{the} \mathrm{surface} \mathrm{from} \mathrm{the}$ ambient atmosphere. In Fig. 6 the special spectral region of 400-700 $\mathrm{cm}^{-1}$ is shown [46]. The peaks around $480-440 \mathrm{~cm}^{-1}$ are assigned to vibration levels of the Ti-N bond [47]. With an increase of nitrogen content, these peaks become stronger, which denotes more Ti-N bonds in the NPs [48]. Several peaks were found in the wavenumber region ranged from 400 to $440 \mathrm{~cm}^{-1}$, and all of them can be attributed to the stretching vibration of the Ti-O-Ti bond [49]. However, their intensity in the N-rich samples was relatively low, indicating that the network of Ti-O-Ti was not well developed there [50]. It is known, that anatase-rich NPs gives only one peak at $550 \mathrm{~cm}^{-1}$, while the rutile NPs gives two peaks at 530 and $640 \mathrm{~cm}^{-1}$, respectively [51]. So, all the peaks at $435-650 \mathrm{~cm}^{-1}$ may be also ascribed to the stretching vibrations of $\mathrm{Ti}-\mathrm{O}$ and $\mathrm{Ti}-\mathrm{O}-\mathrm{Ti}$ bonds, respectively. However, it is necessary to keep in mind, that in the above-mentioned area of wavenumbers the Ti-N - and Ti-O bands are usually overlapped [52].

The inset in Fig. 6 shows the dependence of saturation magnetization from the magnitude of FTIR peak No.1 for as-prepared NPs. As was shown, the $\sigma_{\mathrm{s}}$ increases with peak magnitude and some of its correlations with N/O ratio value seem to be present, which verifies the essential role of the Ti-N subsystem in RTFM evolution.

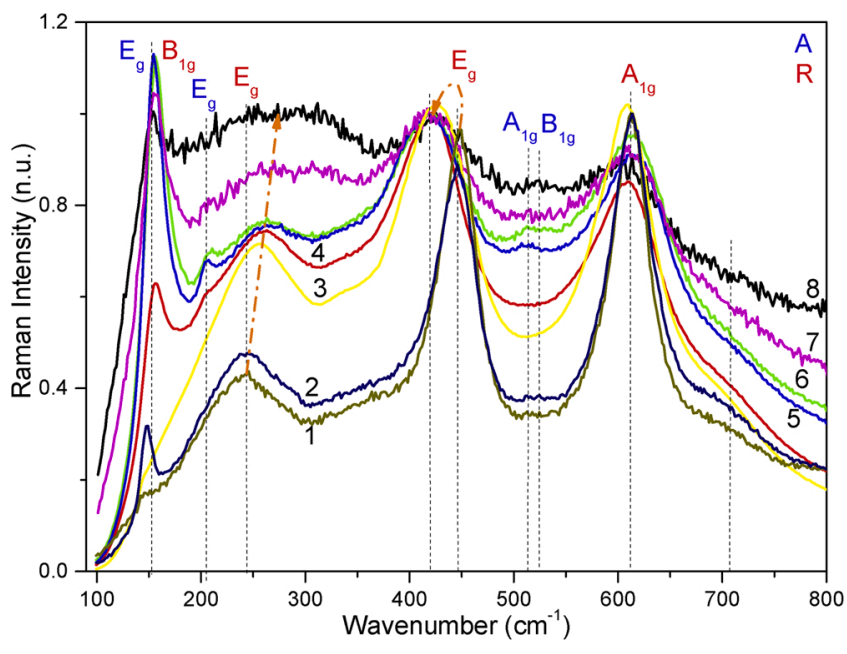

Fig. 7. Raman spectra (normalized) of some NPs: 1 - TNO5, 2 - TNO6, $3-$ TNO8, 4 - TNO3, 5 - TNO2, 6 - TNO4, 7 - TNO7, and 8 - TNO1. A - anatase, R - rutile.

\subsubsection{Raman spectroscopy}

In Fig. 7 the Raman spectra of the NPs are presented. These spectra show the presence of the mixed-phase in the Ti- $N$-Osystem, which varied among the NPs. It should be noted, that part of the peaks are not well defined and constitute an unresolved structure, indicating the coexistence of some disordered phases [53]. For all the NPs rutile peak $\mathrm{E}_{\mathrm{g}}(1)$, which tends to broaden and blue shift the peak position starting from $245 \mathrm{~cm}^{-1}$, partially, with N/O ratio decrease (denoted by the arrow) may be seen. A controversial tendency may be also seen for the rutile peak $\mathrm{E}_{\mathrm{g}}(2)\left(445 \mathrm{~cm}^{-1}\right)$ : redshift and transformation into the peak at 422 $\mathrm{cm}^{-1}$ [54]. The broadening arises mainly owing to the oxygen vacancies and due to phonon confinement effects in the NPs [44].

NPs with large N/O ratio value may consist of nonstoichiometric TiN, and oxygen there exists as a solid solution therein [6]. Since amorphous $\mathrm{TiN}_{\mathrm{x}} \mathrm{O}_{\mathrm{y}}$ was reported to exist on the surface of TiN [55], only a few peaks may be considered as a superimposed with rutile Raman peaks of such compounds for NPs with rich nitrogen content. That may be the peaks at $246 \mathrm{~cm}^{-1}$ for $\mathrm{Ti}_{3-\delta} \mathrm{O}_{4} \mathrm{~N}$ [56] and at $243 \mathrm{~cm}^{-1}$ for $\mathrm{TiO}_{\mathrm{x}} \mathrm{N}_{\mathrm{y}}$ [54], respectively. The rutile peak at $445 \mathrm{~cm}^{-1}$ may be also superimposed with $444 \mathrm{~cm}^{-1}$ peak of $\mathrm{TiO}_{\mathrm{x}} \mathrm{N}_{\mathrm{y}}$ and the peaks near $205 \mathrm{~cm}^{-1}$ rather than belonging to the $\mathrm{TiO}_{\mathrm{x}}$ compounds [54]. The intensity peaks are generally weakly attributable to the metastable $\mathrm{TiO}_{\mathrm{x}}$ phases [57].

In NPs with small N/O ratio value, we can see the Raman peaks of $\mathrm{TiO}_{\mathrm{x}}$ compounds, containing anatase as the main phase $\left(\mathrm{A}_{1 \mathrm{~g}}, \mathrm{~B}_{1 \mathrm{~g}}\right.$, $512-520 \mathrm{~cm}^{-1}$ ). In NPs 5,6,2,4 these peaks may be overlapped with weak peaks discovered at $518 \mathrm{~cm}^{-1}$ [58] and $520 \mathrm{~cm}^{-1}$ [59] for $\mathrm{TiN}_{\mathrm{x}} \mathrm{O}_{\mathrm{y}}$, and at $515 \mathrm{~cm}^{-1}$ for $\mathrm{TiO}_{\mathrm{x}}$ [54], respectively. It should be also noted, that there are some overlapped signals between anatase $\mathrm{TiO}_{2}$ and $\mathrm{TiN}$. As a result of that, the O-Ti-N and Ti-N bonds do not lead to any new Raman bands [6]. The first strongest low-frequency $\mathrm{E}_{\mathrm{g}}$ peak presents a blue shift and broadening relative to that observed in anatase nanocrystals of large size due to the breakdown of $k=0$ Raman selection rule induced by phonon confinement [60]. In the TNO6 NPs oxygen defects result in the broadening and shifting of the $\mathrm{E}_{\mathrm{g}}$ line to higher wavenumber [61]. The phonon lifetime is shorter in these NPs also due to phonon confinement in the small nanocrystallites [62]. We discovered the blue shift from 144 $\mathrm{cm}^{-1}$ for pure anatase to $154-156 \mathrm{~cm}^{-1}$ for NPs understudy close to that reported earlier [57]. This indicates that the anatase phase is preserved on the surface after $\mathrm{N}$ doping [36].

The results arose from the analysis of Raman spectra, supported a hypothesis regarding the predominant role of vacancies, which may be suggested for the RTFM origin in the NPs.

Following the results produced in [63], it may assume that $V_{O}$ and $V_{N}$ 


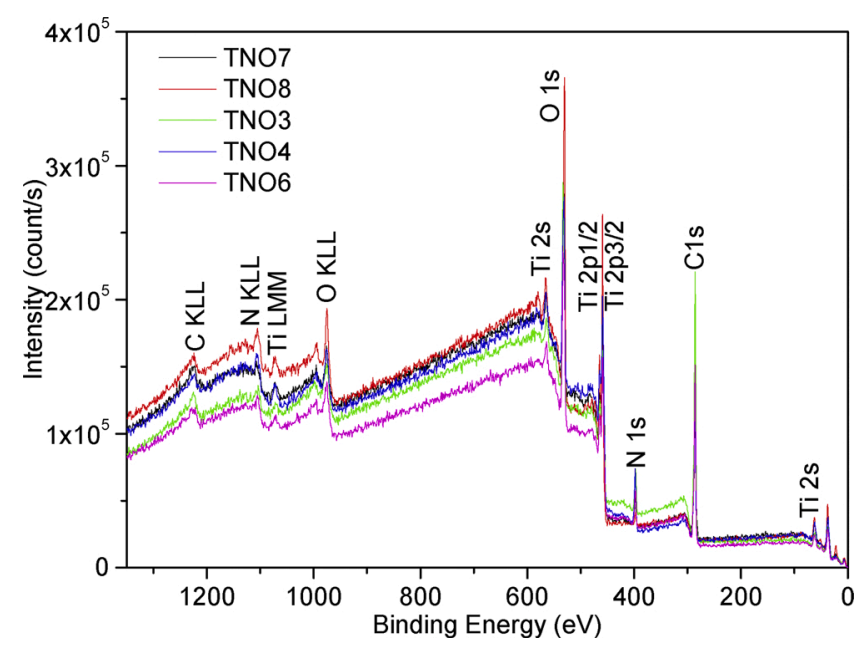

Fig. 8. Survey XPS spectra of some NPs. The numbers of curves correspond to the numbers of NPs in Tables 1 and 2.

vacancies are generating the electron-rich active sites. The $\mathrm{V}_{O}$ is dispersed in single- and double-cluster forms in the anatase and rutile phases, respectively, in both bulk and surface. The $\mathrm{V}_{O}$ distribution is homogeneous in anatase and heterogeneous in rutile bulk, respectively. Since the $\mathrm{TiO}_{\mathrm{x}} \mathrm{N}_{\mathrm{y}}$ system is a much more defective system, we are sure that thedistribution of vacancies in the material (on its surface and subsurfaces) could potentially create more active sites, especially, on the phase interfaces [63].

\subsubsection{XPS}

The elementary composition and surface chemistry of all the samples were analyzed by using XPS. The XPS results indicate that all the samples are only containing Ti, O, N, and C elements (Fig. 8). XPS survey scan spectra of some NPs were recorded to show the Ti 2p, N 1s, O 1s, and $\mathrm{C}$ 1s core-level regions.

All the XPS peaks were deconvoluted by Origin 2018 software with the Gaussian profile function, including a fixed XPS baseline model in the Shirley computation range method [22]. As an example, high-resolution XPS spectra for the different regions of TNO6 NPs are presented in Fig. 9.

In Fig. 9a the deconvoluted doublet of the Ti $2 p$ peaks shows a specific structure that can be ascribed to the presence of Ti- $\mathrm{N}-\mathrm{O}$ compounds. The Ti $2 \mathrm{p}_{3 / 2}$ peak with the binding energies (BE) is equal to $454.5 \mathrm{eV}, 456.7 \mathrm{eV}$, and $458.3 \mathrm{eV}$, as well as Ti $2 \mathrm{p}_{1 / 2}$ peak with $\mathrm{BE}=$ $460.4 \mathrm{eV}, 461.9 \mathrm{eV}$, and $463.9 \mathrm{eV}$ components, can be resolved in the collected spectrum, which is close to the values reported earlier $[58,64]$. For the Ti $2 p_{3 / 2}$ peak areas, the first peak component may be attributed to Ti-N bonds [22,65]. It is known, that the peak at $458.3 \mathrm{eV}$ is indicative of Ti-O bonds, which is typical for Ti (IV) in the $\mathrm{TiO}_{2}$ oxide $[23,66,67]$. The Ti 2p spectral deconvolution was also showed the presence of a peak at $\mathrm{BE}=456.7 \mathrm{eV}$. Since this binding energy is close to that of both $\mathrm{TiO}_{\mathrm{x}}$ $(\mathrm{x}<2)$ and $\mathrm{TiN}_{\mathrm{x}} \mathrm{O}_{\mathrm{y}}$ [68], we need to consider the $\mathrm{N} 1 \mathrm{~s}$ spectra [64].

In Fig. $9 \mathrm{~b}$ the $\mathrm{N} 1 \mathrm{~s}$ core-level region is divided into four different peaks with $\mathrm{BE}=395.6 \mathrm{eV}, 396.8 \mathrm{eV}, 398.4 \mathrm{eV}$ and $399.7 \mathrm{eV}$, respectively. The peak located at $395.6 \mathrm{eV}$ is attributed to oxygen substitution with nitrogen $(\beta-N)$ in the titania lattice [69]. The $\mathrm{N} 1$ s peak appears at the binding energy of $396.8 \mathrm{eV}$ is likely due to the formation of titanium ions with higher valence state caused by higher oxygen content, which further corroborates the formation of $\mathrm{TiN}\left(\mathrm{TiN}_{\mathrm{x}} \mathrm{O}_{\mathrm{y}}\right)$ species [22,70-72]. The peak located at $398.4 \mathrm{eV}$ may be attributed to the anionic $\mathrm{N}$ in Ti-O-N, which is the interstitial $\mathrm{N}$, indicating that $\mathrm{N}$ atoms penetrated the lattice to form interstitial Ti-O-N bonds $[59,73,74]$. The peak located near $399.7 \mathrm{eV}$ can be assigned either to molecular nitrogen $\left(\mathrm{N}_{2}\right)$ bonded to surface defects, or to chemisorbed $\mathrm{N}$ species bonded to surface $\mathrm{O}$ sites, or to $\mathrm{C}-\mathrm{N}$ bonds $[38,46,64,75]$.

In the $\mathrm{O} 1 \mathrm{~s}$ region, an asymmetric peak was observed (Fig. 9c). This peak is composed of three contributions with $\mathrm{BE}=529.8 \mathrm{eV}, 531.9 \mathrm{eV}$, and $533.3 \mathrm{eV}$, respectively. The first peak was attributed to the contribution of O-Ti bonds in the crystal lattice of titanium oxide and oxynitride compounds $[65,76]$. The second one is the result of the presence of $\mathrm{Ti}-\mathrm{O}-\mathrm{N}$ or $\mathrm{Ti}-\mathrm{N}-\mathrm{O}$ structures [77], and the last peak is related to the $\mathrm{C}=\mathrm{O}$ bonds in carboxylic groups [78].

In the $\mathrm{C} 1 \mathrm{~s}$ region (Fig. 9d) the binding energies of peaks are at 284.8
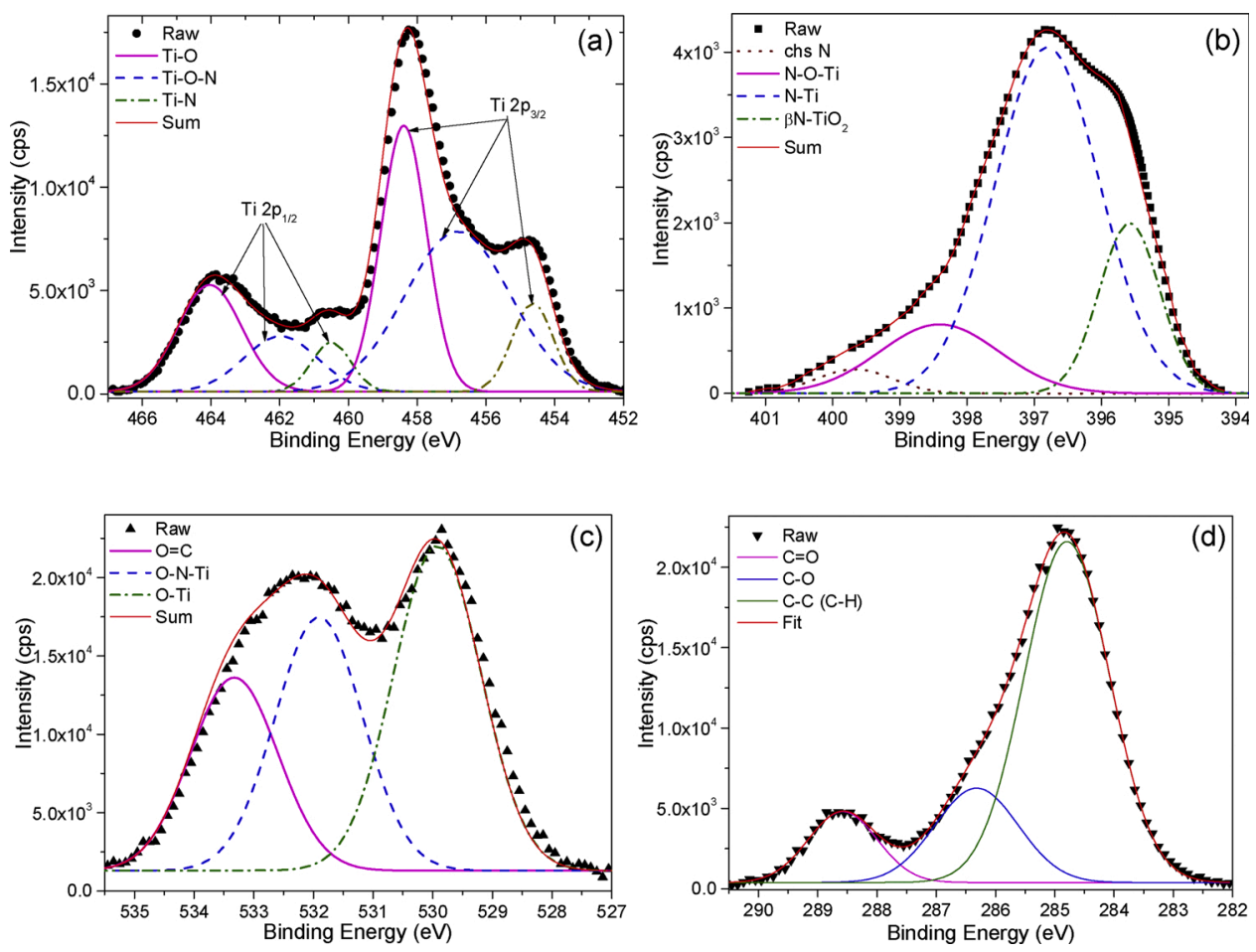

Fig. 9. High-resolution XPS spectra of TNO6 NPs in the core level regions: (a) Ti 2p, (b) N 1s, (c) O 1s, and (d) C 1s. 
Table 3

Curves fitting results for some of the NPs: Ti 2p, N 1s, O 1s, and C 1s of XPS spectra.

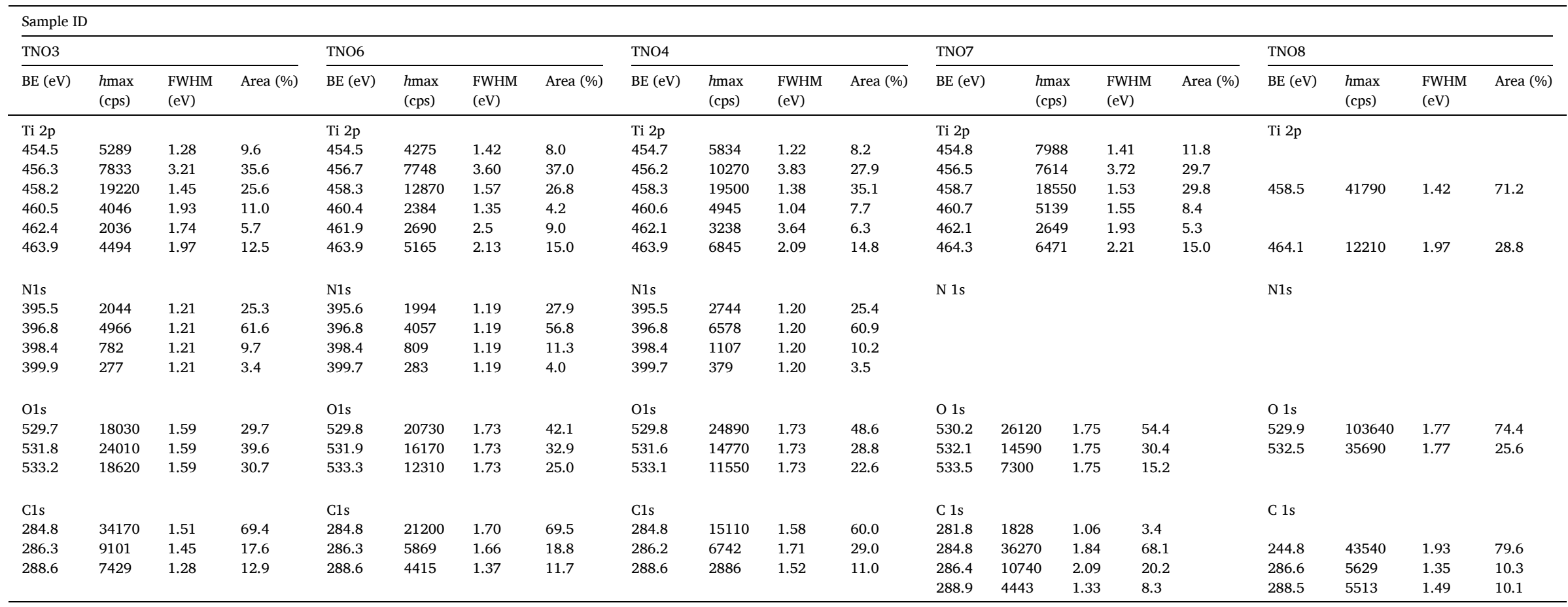




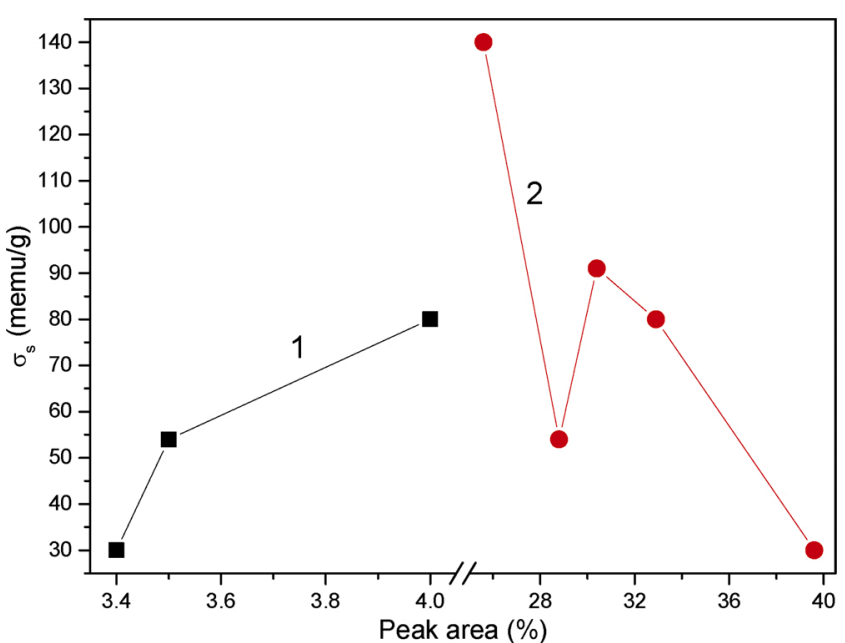

Fig. 10. The saturation magnetization of some NPs $v s$. their XPS peak areas: (1) $\mathrm{N}$ 1s (Chs $\mathrm{N}$ ) and (2) O 1s (O-N-Ti).

$\mathrm{eV}, 286.3$, and $288.6 \mathrm{eV}$. The peak at $284.8 \mathrm{eV}$ corresponds to the carbon instrumental contaminations ( $\mathrm{C}-\mathrm{C}$ bonds) [46]. The second peak was attributed to the $\mathrm{C}-\mathrm{O}$ bonds [44], and the third one - to the $\mathrm{C}=\mathrm{O}$ bonds $[46,79]$, respectively. It should be noted, that in the samples residual amounts of carbonyl compounds and adventitious carbon were unavoidable due to their exposition to air.

The determined values of BE, maximum height $\left(h_{\max }\right)$, FWHM, and relative areas (in \%) of all the fitted components are listed in Table 3.

Since the surface compositions and chemical states were determined using XPS spectra, giving the binding energies of oxygen and titanium on the particle surface, these data could provide some information concerning the origin of magnetization in the NPs.

In Fig. 10 the data regarding some NPs from Table 3 shows two dependencies of $\sigma_{\mathrm{s}} v s$. corresponded peak areas. A progressive increase in the peak areas of $\mathrm{N} 1 \mathrm{~s}$ ( $\mathrm{Chs} \mathrm{N}$ ) and $\mathrm{O} 1 \mathrm{~s}$ (O-N-Ti) components are accompanied by an increase and decrease in $\sigma_{\mathrm{s}}$, respectively. As it was already mentioned above, these two XPS components may be related to the $\mathrm{V}_{\mathrm{N}}$ and $\mathrm{V}_{\mathrm{O}}$ defects.

The coexistence of $\mathrm{V}_{\mathrm{Ti}}, \mathrm{V}_{\mathrm{N}}, \mathrm{V}_{\mathrm{O}}$ vacancies considered to study the origin of ferromagnetic ordering in the Ti- $N$-O system. RTFM coupling between two $V_{T i}$ was enhanced after $V_{O}$ and $V_{N}$, are introduced. The electrons induced by the last vacancies mediate the long-range FM exchange interaction between two distant $\mathrm{V}_{\mathrm{Ti}}$, which produce local moments, while the electrons induced by $\mathrm{V}_{\mathrm{O}}$ and $\mathrm{V}_{\mathrm{N}}$ could be mediated the long-range $\mathrm{FM}$ exchange interaction [80]. However, $\mathrm{V}_{\mathrm{O}}$ and $\mathrm{V}_{\mathrm{N}}$ are the concurrent species in the fight for interaction with $\mathrm{V}_{\mathrm{Ti}}$ sites. Because of that, the Ti- $N-\mathrm{O}$ system does not achieve large $\sigma_{\mathrm{s}}$ values compared to that in the Ti-N or Ti-O system [22,23].

\section{Conclusion}

$\mathrm{TiN}_{\mathrm{x}}-\mathrm{TiO}_{\mathrm{y}}$ aerosol-generated nanoparticles, ranging in average particle sizes from $27-120 \mathrm{~nm}$, can be fabricated by using the levitation-jet method through condensation of titanium vapor in an inert-gas flow with an appropriate addition of reactive gas. Results from SEM, TEM, BET, XRD, UV-vis, FT-IR, Raman, and XPS investigations demonstrate the predominant role of nitrogen and oxygen vacancies at the interfaces between titanium nitride, anatase, rutile, as well as the other mixed Ti$\mathrm{N}$-O phases in the evolution of RTFM.

The synthesized mixed-phase nanoparticles are ferromagnetic at room temperature with maximum saturation magnetization $\left(\sigma_{s}\right)$ of up to $0.14 \mathrm{emu} / \mathrm{g}$ and coercive force ranging in $40-130$ Oe. The $\sigma_{\mathrm{s}}$ values of $\mathrm{TiN}_{\mathrm{x}}-\mathrm{TiO}_{\mathrm{y}} \mathrm{NPs}$ are dependent on the N/O ratio and reach maximum when $\mathrm{N}$ and $\mathrm{O}$ vacancies content in as-prepared samples was the same.
Interestingly an increasing magnitude of certain FT-IR peak led win an increase of $\sigma_{\mathrm{s}}$ of NPs. An increase in $\sigma_{\mathrm{s}}$ value takes place with a corresponding increase in the area of defined XPS peaks for core-level $\mathrm{N} 1 \mathrm{~s}$ and a decrease in the peak area of core-level $\mathrm{O} 1 \mathrm{~s}$. For the first time, a temporary "turn-off" effect of magnetization in hysteresis loops of some NPs was discovered. This behavior may be interpreted in terms of the defect structure of the phase interfaces, containing Ti, $\mathrm{N}$, and $\mathrm{O}$ vacancies, whose concentrations and degree of interactions may be varied by the NPs preparation procedure. The obtained results might be used to develop knowledge regarding the origin of RTFM, as well as becoming the base for developing advanced semiconducting materials for using in the spintronic applications.

\section{References}

[1] L.M.C. Pereira, Experimentally evaluating the origin of dilute magnetism in nanomaterials, J. Phys. D: Appl. Phys. 50 (2017) 393002, https://doi.org/ 10.1088/1361-6463/aa801f.

[2] M.A. Garcia, E.F. Pinel, Jdl. Venta, A. Quesada, V. Bouzas, J.F. Fernández, J. J. Romero, M.S.M. González, J.L. Costa-Krämer, Sources of experimental errors in the observation of nanoscale magnetism, J. Appl. Phys. 105 (2009), 013925, https://doi.org/10.1063/1.3060808.

[3] I.G. Morozov, O.V. Belousova, M.V. Kuznetcov, Room-temperature ferromagnetism in nanostructured submicron Cd/CdO particles, J. Mater. Sci.: Mater. Electron. 31 (2020) 6664-6670, https://doi.org/10.1007/s10854-020-03222-z.

[4] P. Esquinazi, W. Hergert, D. Spemann, A. Setzer, A. Ernst, Defect-induced magnetism in solids, IEEE Trans. Magn. 49 (2013) 4668-4674, https://doi.org/ 10.1109/TMAG.2013.2255867.

[5] P.-Z. Si, C.J. Choi, O. Tegus, E. Brück, D.Y. Geng, Z.D. Zhang, Air stability and magnetic properties of GdN, TiN, and (Gd,Ti)N nanoparticles, J. Nanopart. Res. 10 (2008) 53-58, https://doi.org/10.1007/s11051-007-9232-8.

[6] C. Gong, C. Yan, J. Zhang, X. Cheng, H. Pan, C. Zhang, L. Yu, Z. Zhang, Roomtemperature ferromagnetism evolution in nanostructured titanium nitride superconductors-the influence of structural defects, J. Mater. Chem. 21 (2011) 15273-15278, https://doi.org/10.1039/C1JM12359A.

[7] N.H. Hong, J. Sakai, N. Poirot, V. Brizé, Room-temperature ferromagnetism observed in undoped semiconducting and insulating oxide thin films, Physical Review B 73 (2006) 132404, https://doi.org/10.1103/PhysRevB.73.132404.

[8] A. Sundaresan, C.N.R. Rao, Ferromagnetism as a universal feature of inorganic nanoparticles, Nano Today 4 (2009) 96-106, https://doi.org/10.1016/j. nantod.2008.10.002.

[9] G. Drera, M.C. Mozzati, P. Galinetto, Y. Diaz-Fernandez, L. Malavasi, F. Bondino, M. Malvestuto, L. Sangaletti, Enhancement of room temperature ferromagnetism in $\mathrm{N}$-doped $\mathrm{TiO}_{2-\mathrm{x}}$ rutile: correlation with the local electronic properties, Appl. Phys. Lett. 97 (2010), 012506, https://doi.org/10.1063/1.3458699.

[10] Q. Zhao, P. Wu, B.L. Li, Z.M. Lu, E.Y. Jiang, Activation of room-temperature ferromagnetism in nonstoichiometric $\mathrm{TiO}_{2} \delta$ powders by oxygen vacancies, J. Appl. Phys. 104 (2008), 073911, https://doi.org/10.1063/1.2999501.

[11] Q. Wen, H. Zhang, Q. Yang, D. Gu, Y. Li, Y. Liu, J. Shen, J.Q. Xiao, Magnetic characteristics of carbon-doped nanocrystalline $\mathrm{TiO}_{2}$, IEEE Trans. Magn. 45 (2009) 4096-4099, https://doi.org/10.1109/TMAG.2009.2024317.

[12] B. Choudhury, A. Choudhury, Room temperature ferromagnetism in defective $\mathrm{TiO}_{2}$ nanoparticles: role of surface and grain boundary oxygen vacancies, J. Appl. Phys. 114 (2013) 203906, https://doi.org/10.1063/1.4833562.

[13] S. Ghosh, G.G. Khan, K. Mandal, A. Samanta, P.M.G. Nambissan, Evolution of vacancy-type defects, phase transition, and intrinsic ferromagnetism during 
annealing of nanocrystalline $\mathrm{TiO}_{2}$ studied by positron annihilation spectroscopy, J. Phys. Chem. C 117 (2013) 8458-8467, https://doi.org/10.1021/jp3115836.

[14] C. Gómez-Polo, S. Larumbe, J.M. Pastor, Room temperature ferromagnetism in non-magnetic doped $\mathrm{TiO}_{2}$ nanoparticles, J. Appl. Phys. 113 (2013), 17B511, https://doi.org/10.1063/1.4795615.

[15] S.K.S. Patel, S. Kurian, N.S. Gajbhiye, Room-temperature ferromagnetism of Fedoped $\mathrm{TiO}_{2}$ nanoparticles driven by oxygen vacancy, Mater. Res. Bull. 48 (2013) 655-660, https://doi.org/10.1016/j.materresbull.2012.11.031.

[16] Q. Wang, X. Wei, J. Dai, J. Jiang, X. Huo, Influence of annealing process on ferromagnetism of undoped $\mathrm{TiO}_{2}$ nanoparticles prepared by sol-gel method, Mater. Sci. Semicond. Process. 21 (2014) 111-115, https://doi.org/10.1016/j. mssp. 2014.01.004.

[17] P.K. Singh, S. Mukherjee, C.K. Ghosh, S. Maitra, Influence of precursor type on structural, morphological, dielectric and magnetic properties of $\mathrm{TiO}_{2}$ nanoparticles, Cerâmica 63 (2017) 549-556.

[18] N. Rajkumar, K. Ramachandran, Oxygen deficiency and room temperature ferromagnetism in undoped and cobalt-doped $\mathrm{TiO}_{2}$ nanoparticles, IEEE Trans. Nanotechnol. 10 (2011) 513-519, https://doi.org/10.1109/ TNANO.2010.2049745.

[19] A. Chanda, K. Rout, M. Vasundhara, S.R. Joshi, J. Singh, Structural and magnetic study of undoped and cobalt doped $\mathrm{TiO}_{2}$ nanoparticles, RSC Adv. 8 (2018) 10939-10947, https://doi.org/10.1039/C8RA00626A.

[20] M. Parras, Á. Varela, R. Cortés-Gil, K. Boulahya, A. Hernando, J.M. GonzálezCalbet, Room-temperature ferromagnetism in reduced rutile $\mathrm{TiO}_{2-} \delta$ nanoparticles, J. Phys. Chem. Lett. 4 (2013) 2171-2176, https://doi.org/10.1021/jz401115q.

[21] S. Wang, L. Pan, J.-J. Song, W. Mi, J.-J. Zou, L. Wang, X. Zhang, Titanium-defected undoped anatase $\mathrm{TiO}_{2}$ with p-type conductivity, room-temperature ferromagnetism, and remarkable photocatalytic performance, J. Am. Chem. Soc. 137 (2015) 2975-2983, https://doi.org/10.1021/ja512047k.

[22] I.G. Morozov, O.V. Belousova, O.A. Belyakov, I.P. Parkin, S. Sathasivam, M. V. Kuznetcov, Titanium nitride room-temperature ferromagnetic nanoparticles, J. Alloys Compd. 675 (2016) 266-276, https://doi.org/10.1016/j. jallcom.2016.03.111.

[23] I.G. Morozov, S. Sathasivam, O.V. Belousova, I.V. Shishkovsky, M.V. Kuznetcov, Room temperature ferromagnetism in mixed-phase titania nanoparticles produced by the levitation-jet generator, J. Mater. Sci.: Mater. Electron. 29 (2018) 3304-3316, https://doi.org/10.1007/s10854-017-8266-7.

[24] H. Peng, J. Li, S.-S. Li, J.-B. Xia, Possible origin of ferromagnetism in undoped anatase $\mathrm{TiO}_{2}$, Physical Review B 79 (2009), 092411, https://doi.org/10.1103/ PhysRevB.79.092411.

[25] C. Sudakar, P. Kharel, R. Suryanarayanan, J.S. Thakur, V.M. Naik, R. Naik, G. Lawes, Room temperature ferromagnetism in vacuum-annealed $\mathrm{TiO}_{2}$ thin films, J. Magn. Magn. Mater. 320 (2008) L31-L36, https://doi.org/10.1016/j. jmmm.2007.07.026.

[26] G. Mattioli, F. Filippone, P. Alippi, A. Amore Bonapasta, Ab initio study of the electronic states induced by oxygen vacancies in rutile and anatase $\mathrm{TiO}_{2}$, Physical Review B 78 (2008) 241201, https://doi.org/10.1103/PhysRevB.78.241201.

[27] A.Y. Yermakov, D.W. Boukhvalov, A.S. Volegov, M.A. Uimin, G.S. Zakharova, A. V. Korolev, E.V. Rosenfeld, V.V. Mesilov, A.S. Minin, V.R. Galakhov, L. S. Molochnikov, A.F. Gubkin, A.M. Murzakaev, S.F. Konev, Unconventional magnetism of non-uniform distribution of $\mathrm{Co}$ in $\mathrm{TiO}_{2}$ nanoparticles, J. Alloys Compd. 826 (2020) 154194, https://doi.org/10.1016/j.jallcom.2020.154194.

[28] J. Osorio-Guillén, S. Lany, S.V. Barabash, A. Zunger, Nonstoichiometry as a source of magnetism in otherwise nonmagnetic oxides: magnetically interacting cation vacancies and their percolation, Physical Review B 75 (2007) 184421, https://doi. org/10.1103/PhysRevB.75.184421.

[29] Y.G. Morozov, O.V. Belousova, M.V. Kuznetsov, D. Ortega, I.P. Parkin, Electric field-assisted levitation-jet aerosol synthesis of $\mathrm{Ni} / \mathrm{NiO}$ nanoparticles, J. Mater. Chem. 22 (2012) 11214-11223, https://doi.org/10.1039/C2JM31233F.

[30] S. Batakrushna, G. P. K, D. Soumen, I. Kenji, F. Minoru, Oxygen vacancy-mediated enhanced ferromagnetism in undoped and Fe-doped $\mathrm{TiO}_{2}$ nanoribbons, J. Phys. D: Appl. Phys. 47 (2014) 235304, https://doi.org/10.1088/0022-3727/47/23/ 235304.

[31] I.G. Morozov, O.V. Belousova, D. Ortega, M.K. Mafina, M.V. Kuznetcov, Structural, optical, XPS and magnetic properties of $\mathrm{Zn}$ particles capped by $\mathrm{ZnO}$ nanoparticles, J. Alloys Compd. 633 (2015) 237-245, https://doi.org/10.1016/j. jallcom.2015.01.285.

[32] M.V. Kuznetsov, Y.G. Morozov, O.V. Belousova, D. Ortega, Ferromagnetic Zn/ZnO nanoparticles, Inorg. Mater. 50 (2014) 369-378, https://doi.org/10.1134/ s0020168514040104.

[33] M.V. Kuznetcov, O.V. Belousova, D. Ortega, I.G. Morozov, Ferromagnetic nanoparticles in Sn-O system, Inorg. Mater. 50 (2014) 793-802, https://doi.org/ 10.1134/s0020168514080111.

[34] S.K. Misra, S.I. Andronenko, D. Tipikin, J.H. Freed, V. Somani, O. Prakash, Study of paramagnetic defect centers in as-grown and annealed $\mathrm{TiO}_{2}$ anatase and rutile nanoparticles by a variable-temperature X-band and high-frequency $(236 \mathrm{GHz})$ EPR, J. Magn. Magn. Mater. 401 (2016) 495-505, https://doi.org/10.1016/j. jmmm.2015.10.072.

[35] F. Borgatti, C. Park, A. Herpers, F. Offi, R. Egoavil, Y. Yamashita, A. Yang, M. Kobata, K. Kobayashi, J. Verbeeck, G. Panaccione, R. Dittmann, Chemical insight into electroforming of resistive switching manganite heterostructures, Nanoscale 5 (2013) 3954-3960, https://doi.org/10.1039/C3NR00106G.

[36] R. Jaiswal, J. Bharambe, N. Patel, A. Dashora, D.C. Kothari, A. Miotello, Copper and nitrogen co-doped $\mathrm{TiO}_{2}$ photocatalyst with enhanced optical absorption and catalytic activity, Appl. Catal., B 168-169 (2015) 333-341, https://doi.org/ 10.1016/j.apcatb.2014.12.053.
[37] J. Tauc, Optical properties and electronic structure of amorphous Ge and Si, Mater. Res. Bull. 3 (1968) 37-46, https://doi.org/10.1016/0025-5408(68)90023-8.

[38] F. Spadavecchia, G. Cappelletti, S. Ardizzone, C.L. Bianchi, S. Cappelli, C. Oliva, P. Scardi, M. Leoni, P. Fermo, Solar photoactivity of nano-N-TiO 2 from tertiary amine: role of defects and paramagnetic species, Appl. Catal., B 96 (2010) 314-322, https://doi.org/10.1016/j.apcatb.2010.02.027.

[39] X. Cheng, X. Yu, Z. Xing, J. Wan, Enhanced photocatalytic activity of nitrogen doped $\mathrm{TiO}_{2}$ anatase nano-particle under simulated sunlight irradiation, Energy Procedia 16 (2012) 598-605, https://doi.org/10.1016/j.egypro.2012.01.096.

[40] K.M. Reddy, V.M. Manorama, A.R. Reddy, Bandgap studies on anatase titanium dioxide nanoparticles, Mater. Chem. Phys. 78 (2003) 239-245, https://doi.org/ 10.1016/S0254-0584(02)00343-7.

[41] L.J. Alemany, M.A. Bañares, E. Pardo, F. Martín-Jiménez, J.M. Blasco, Morphological and structural characterization of a titanium dioxide system, Mater. Charact. 44 (2000) 271-275, https://doi.org/10.1016/S1044-5803(99)00066-2.

[42] E. Hernández-Rodríguez, A. Márquez-Herrera, A. Zapata-Navarro, Optical and structural characterization of $\mathrm{TiO}_{\mathrm{x}} \mathrm{N}_{\mathrm{y}}$ films deposited by reactive magnetron sputtering, Revista Mexicana De Fisica (S55) (2009) 102-104.

[43] J. Xu, Y. Ao, D. Fu, C. Yuan, A simple route to synthesize highly crystalline N-doped $\mathrm{TiO}_{2}$ particles under low temperature, J. Cryst. Growth 310 (2008) 4319-4324, https://doi.org/10.1016/j.jcrysgro.2008.07.045.

[44] R. Verma, S.K. Samdarshi, Correlating oxygen vacancies and phase ratio/interface with efficient photocatalytic activity in mixed phase $\mathrm{TiO}_{2}$, J. Alloys Compd. 629 (2015) 105-112, https://doi.org/10.1016/j.jallcom.2014.12.218.

[45] N.G. Moustakas, A.G. Kontos, V. Likodimos, F. Katsaros, N. Boukos, D. Tsoutsou, A. Dimoulas, G.E. Romanos, D.D. Dionysiou, P. Falaras, Inorganic-organic coreshell titania nanoparticles for efficient visible light activated photocatalysis, Appl. Catal., B 130-131 (2013) 14-24, https://doi.org/10.1016/j.apcatb.2012.10.007.

[46] X.F. Lei, X.X. Xue, H. Yang, C. Chen, X. Li, M.C. Niu, X.Y. Gao, Y.T. Yang, Effect of calcination temperature on the structure and visible-light photocatalytic activities of (N, S and C) co-doped $\mathrm{TiO}_{2}$ nano-materials, Appl. Surf. Sci. 332 (2015) 172-180, https://doi.org/10.1016/j.apsusc.2015.01.110.

[47] M.-K. Lee, H.-S. Kang, W.-W. Kim, J.-S. Kim, W.-J. Lee, Characteristics of TiN film deposited on stellite using reactive magnetron sputter ion plating, J. Mater. Res. 12 (1997) 2393-2400, https://doi.org/10.1557/JMR.1997.0317.

[48] L.I. Wei, C. Jun-Fang, Growth of TiN films at low temperature, Appl. Surf. Sci. 253 (2007) 7019-7023, https://doi.org/10.1016/j.apsusc.2007.02.028.

[49] M.R. Mohammadi, D.J. Fray, A. Mohammadi, Sol-gel nanostructured titanium dioxide: controlling the crystal structure, crystallite size, phase transformation, packing and ordering, Microporous Mesoporous Mater. 112 (2008) 392-402, https://doi.org/10.1016/j.micromeso.2007.10.015.

[50] Z. Li, M. Kawashita, M. Doi, Sol-gel synthesis and characterization of magnetic $\mathrm{TiO}_{2}$ microspheres, J. Ceram. Soc. Jpn. 118 (2010) 467-473, https://doi.org/ 10.2109/jcersj2.118.467.

[51] J. Wang, R. Li, Z. Zhang, W. Sun, X. Wang, R. Xu, Z. Xing, X. Zhang, Degradation of hazardous dyes in wastewater using nanometer mixed crystal $\mathrm{TiO}_{2}$ powders under visible light irradiation, Water, Air, Soil Pollut. 189 (2008) 225-237, https://doi. org/10.1007/s11270-007-9570-2.

[52] C. Oliveira, L. Gonçalves, B.G. Almeida, C.J. Tavares, S. Carvalho, F. Vaz, R. Escobar_Galindo, M. Henriques, M. Susano, R. Oliveira, XRD and FTIR analysis of Ti-Si-C-ON coatings for biomedical applications, Surf. Coat. Technol. 203 (2008) 490-494, https://doi.org/10.1016/j.surfcoat.2008.06.121.

[53] M. Fusi, E. Maccallini, T. Caruso, C.S. Casari, A. Li Bassi, C.E. Bottani, P. Rudolf, K. C. Prince, R.G. Agostino, Surface electronic and structural properties of nanostructured titanium oxide grown by pulsed laser deposition, Surf. Sci. 605 (2011) 333-340, https://doi.org/10.1016/j.susc.2010.10.039.

[54] A.S. Bolokang, D.E. Motaung, C.J. Arendse, T.F.G. Muller, Morphology and structural development of reduced anatase- $\mathrm{TiO}_{2}$ by pure Ti powder upon annealing and nitridation: synthesis of $\mathrm{TiO}_{\mathrm{x}}$ and $\mathrm{TiO}_{\mathrm{x}} \mathrm{N}_{\mathrm{y}}$ powders, Mater. Charact. 100 (2015) 41-49, https://doi.org/10.1016/j.matchar.2014.11.026.

[55] M. Radecka, E. Pamula, A. Trenczek-Zajac, K. Zakrzewska, A. Brudnik, E. Kusior, N. T.H. Kim-Ngan, A.G. Balogh, Chemical composition, crystallographic structure and impedance spectroscopy of titanium oxynitride $\operatorname{TiN}_{\mathrm{x}} \mathrm{O}_{\mathrm{y}}$ thin films, Solid State Ionics 192 (2011) 693-698, https://doi.org/10.1016/j.ssi.2010.07.021.

[56] G. Hyett, M.A. Green, I.P. Parkin, Ultra-violet light activated photocatalysis in thin films of the titanium oxynitride, $\mathrm{Ti}_{3}{ }_{3} \delta \mathrm{O}_{4} \mathrm{~N}$, J. Photochem. Photobiol., A 203 (2009) 199-203, https://doi.org/10.1016/j.jphotochem.2009.01.020.

[57] J. Blazevska-Gilev, V. Jandová, J. Kupčík, Z. Bastl, J. Šubrt, P. Bezdička, J. Pola, Laser hydrothermal reductive ablation of titanium monoxide: hydrated TiO particles with modified Ti/O surface, J. Solid State Chem. 197 (2013) 337-344, https://doi.org/10.1016/j.jssc.2012.09.023.

[58] B. Subramanian, C.V. Muraleedharan, R. Ananthakumar, M. Jayachandran, A comparative study of titanium nitride (TiN), titanium oxy nitride (TiON) and titanium aluminum nitride (TiAlN), as surface coatings for bio implants, Surf. Coat. Technol. 205 (2011) 5014-5020, https://doi.org/10.1016/j.surfcoat.2011.05.004.

[59] S. Lee, I.-S. Cho, D.K. Lee, D.W. Kim, T.H. Noh, C.H. Kwak, S. Park, K.S. Hong, J.K. Lee, H.S. Jung, Influence of nitrogen chemical states on photocatalytic activities of nitrogen-doped $\mathrm{TiO}_{2}$ nanoparticles under visible light, J. Photochem. Photobiol., A 213 (2010) 129-135, https://doi.org/10.1016/j.jphotochem.2010.05.011.

[60] A.I. Kontos, A.G. Kontos, D.S. Tsoukleris, G.D. Vlachos, P. Falaras, Superhydrophilicity and photocatalytic property of nanocrystalline titania sol-gel films, Thin Solid Films 515 (2007) 7370-7375, https://doi.org/10.1016/j. tsf.2007.02.082.

[61] B. Choudhury, A. Choudhury, Local structure modification and phase transformation of $\mathrm{TiO}_{2}$ nanoparticles initiated by oxygen defects, grain size, and 
annealing temperature, Inter. Nano Lett. 3 (2013) 55, https://doi.org/10.1186/ 2228-5326-3-55.

[62] D. Wang, J. Zhao, B. Chen, C. Zhu, Lattice vibration fundamentals in nanocrystalline anatase investigated with raman scattering, J. Phys.: Condens. Matter 20 (2008) 085212, https://doi.org/10.1088/0953-8984/20/8/085212.

[63] Mohammadreza Elahifard, Mohammad Reza Sadrian, Amir Mirzanejad, Reza Behjatmanesh-Ardakani, S. Ahmadvand, Dispersion of defects in $\mathrm{TiO}_{2}$ semiconductor: oxygen vacancies in the bulk and surface of rutile and anatase, Catalysts 10 (2020) 397-407, https://doi.org/10.3390/catal10040397.

[64] X. Song, D. Gopireddy, C.G. Takoudis, Characterization of titanium oxynitride films deposited by low pressure chemical vapor deposition using amide Ti precursor, Thin Solid Films 516 (2008) 6330-6335, https://doi.org/10.1016/j. tsf.2007.12.148.

[65] N. White, A.L. Campbell, J.T. Grant, R. Pachter, K. Eyink, R. Jakubiak, G. Martinez, C.V. Ramana, Surface/interface analysis and optical properties of RF sputterdeposited nanocrystalline titanium nitride thin films, Appl. Surf. Sci. 292 (2014) 74-85, https://doi.org/10.1016/j.apsusc.2013.11.078.

[66] S. Ardizzone, C.L. Bianchi, G. Cappelletti, S. Gialanella, C. Pirola, V. Ragaini, Tailored Anatase/brookite nanocrystalline $\mathrm{TiO}_{2}$. The optimal particle features for liquid- and gas-phase photocatalytic reactions, J. Phys. Chem. C 111 (2007) 13222-13231, https://doi.org/10.1021/jp0741096.

[67] M. Matsuoka, S. Isotani, J.C.R. Mittani, J.F.D. Chubaci, K. Ogata, N. Kuratani, Effects of arrival rate and gas pressure on the chemical bonding and composition in titanium nitride films prepared on $\mathrm{Si}(100)$ substrates by ion beam and vapor deposition, Journal of Vacuum Science \& Technology A 23 (2005) 137-141, https://doi.org/10.1116/1.1839895.

[68] J.F. Marco, A.C. Agudelo, J.R. Gancedo, D. Hanžel, Corrosion resistance of single TiN layers, Ti/TiN bilayers and Ti/TiN/Ti/TiN multilayers on iron under a salt fog spray (phohesion) test: an evaluation by XPS, Surf. Interface Anal. 27 (1999) 71-75, https://doi.org/10.1002/(sici)1096-9918(199902)27:2<71::aidsia469>3.0.co;2-g.

[69] C.J. Tavares, S.M. Marques, S. Lanceros-Méndez, L. Rebouta, E. Alves, N. P. Barradas, F. Munnik, T. Girardeau, J.P. Rivière, N-doped photocatalytic titania thin films on active polymer substrates, J. Nanosci. Nanotechnol. 10 (2010) 1072-1077, https://doi.org/10.1166/jnn.2010.1868.

[70] E. Galvanetto, F.P. Galliano, F. Borgioli, U. Bardi, A. Lavacchi, XRD and XPS study on reactive plasma sprayed titanium-titanium nitride coatings, Thin Solid Films 384 (2001) 223-229, https://doi.org/10.1016/S0040-6090(00)01871-X.
[71] M.J. Powell, C.W. Dunnill, I.P. Parkin, N-doped $\mathrm{TiO}_{2}$ visible light photocatalyst films via a sol-gel route using TMEDA as the nitrogen source, J. Photochem. Photobiol., A 281 (2014) 27-34, https://doi.org/10.1016/j. jphotochem.2014.03.003.

[72] X. Yang, C. Cao, L. Erickson, K. Hohn, R. Maghirang, K. Klabunde, Photo-catalytic degradation of rhodamine $\mathrm{B}$ on $\mathrm{C}-$, S-, N-, and Fe-doped $\mathrm{TiO}_{2}$ under visible-light irradiation, Appl. Catal., B 91 (2009) 657-662, https://doi.org/10.1016/j. apcatb.2009.07.006.

[73] J. Lv, T. Sheng, L. Su, G. Xu, D. Wang, Z. Zheng, Y. Wu, N, S co-doped-TiO $2 /$ fly ash beads composite material and visible light photocatalytic activity, Appl. Surf. Sci. 284 (2013) 229-234, https://doi.org/10.1016/j.apsusc.2013.07.086.

[74] P.Y. Jouan, M.C. Peignon, C. Cardinaud, G. Lempérière, Characterisation of TiN coatings and of the TiN/Si interface by X-ray photoelectron spectroscopy and auger electron spectroscopy, Appl. Surf. Sci. 68 (1993) 595-603, https://doi.org/ 10.1016/0169-4332(93)90241-3.

[75] S.H. Cheung, P. Nachimuthu, A.G. Joly, M.H. Engelhard, M.K. Bowman, S. A. Chambers, $\mathrm{N}$ incorporation and electronic structure in $\mathrm{N}$-doped $\mathrm{TiO}_{2}(110)$ rutile, Surf. Sci. 601 (2007) 1754-1762, https://doi.org/10.1016/j. susc. 2007.01.051.

[76] X. Cheng, X. Yu, Z. Xing, Characterization and mechanism analysis of $\mathrm{N}$ doped $\mathrm{TiO}_{2}$ with visible light response and its enhanced visible activity, Appl. Surf. Sci. 258 (2012) 3244-3248, https://doi.org/10.1016/j.apsusc.2011.11.072.

[77] E. György, A. Pérez del Pino, P. Serra, J.L. Morenza, Depth profiling characterisation of the surface layer obtained by pulsed Nd:YAG laser irradiation of titanium in nitrogen, Surf. Coat. Technol. 173 (2003) 265-270, https://doi.org/ 10.1016/S0257-8972(03)00520-6.

[78] E. Yousefi, M. Ghorbani, A. Dolati, H. Yashiro, M. Outokesh, Preparation of new titanium nitride-carbon nanocomposites in supercritical benzene and their oxygen reduction activity in alkaline medium, Electrochim. Acta 164 (2015) 114-124, https://doi.org/10.1016/j.electacta.2015.02.199.

[79] R. Ananthakumar, B. Subramanian, A. Kobayashi, M. Jayachandran, Electrochemical corrosion and materials properties of reactively sputtered TiN/ TiAlN multilayer coatings, Ceram. Int. 38 (2012) 477-485, https://doi.org/ 10.1016/j.ceramint.2011.07.030.

[80] H. Wang, Z. Zong, Y. Yan, Mechanism of multi-defect induced ferromagnetism in undoped rutile $\mathrm{TiO}_{2}$, J. Appl. Phys. 115 (2014), 233909, https://doi.org/10.1063/ 1.4884223 . 